\title{
Impacts of Ionospheric Scintillation on the BIOMASS P-Band Satellite SAR
}

\author{
Neil C. Rogers, Shaun Quegan, Member, IEEE, Jun Su Kim, and Konstantinos P. Papathanassiou
}

\begin{abstract}
The European Space Agency is conducting studies for a low-earth orbiting polarimetric synthetic aperture radar called BIOMASS to provide global measurements of forest biomass and tree height. Phase scintillation across the synthetic aperture caused by ionospheric irregularities can degrade the impulse response function (IRF) and cause squinting, and its temporal variation can cause decorrelation in repeat-pass interferometry. These effects are simulated for a range of conditions for the baseline BIOMASS system configuration using the Wideband model of scintillation, which predicts that for a dawn-dusk orbit, impacts of scintillation over forest regions are negligible under all conditions except at high latitudes in the North American sector under high sunspot activity. In this sector, single-look IRFs have mean integrated sidelobe ratios (ISLRs) and peak sidelobe ratios (PSLRs) better than 0 and $\mathbf{- 5} \mathrm{dB}$, respectively, at $90 \%$ confidence interval under median solar activity up to the northern tree line $\left(\sim 70^{\circ}\right.$ geomagnetic). Degradation in the mean 3-dB resolution of up to $10 \%$ is predicted, with mean absolute azimuth shifts of the IRF peak of up to $2 \mathrm{~m}$, which increases to $5 \mathrm{~m}$ at high sunspot number. Similar values are found for the dawn and dusk sides, and seasonal variations are negligible for latitudes below the tree line. Repeat-pass interferometric image pairs maintain coherence $>0.8$ up to $50^{\circ} \mathrm{N}$ under median sunspot conditions. Four-look processing improves the ISLR and PSLR by several decibels, but causes significant degradation of the 3-dB resolution due to incoherent averaging of images with different random azimuth shifts.
\end{abstract}

Index Terms-Ionosphere, radio propagation, spaceborne radar, synthetic aperture radar (SAR).

\section{INTRODUCTION}

B IOMASS is a P-band (435-MHz) satellite synthetic aperture radar (SAR) mission under consideration by the European Space Agency. Its principal objective is to measure the woody biomass density and height of forests, with annual global coverage over a five-year mission lifetime, using methods that exploit the quad-polarized SAR covariance matrix [1] and polarimetric interferometric SAR methods [2]. Secondary objectives include imaging of subsurface geology

Manuscript received August 24, 2012; revised December 22, 2012; accepted March 21, 2013. Date of publication June 12, 2013; date of current version December 17, 2013. This work was supported in part by the European Space Agency under Contract 22849/09/NL/JA/ef and in part by the UK Natural Environment Research Council under Grant NE/H003649/1.

N. C. Rogers and S. Quegan are with the School of Mathematics and Statistics, University of Sheffield, Sheffield S3 7RH, U.K. (e-mail: ncrogers@physics.org; s.quegan@sheffield.ac.uk).

J. S. Kim and K. P. Papathanassiou are with the German Aerospace Center, Microwaves and Radar Institute, Wessling D-82230, Germany (e-mail: junsu.kim@dlr.de; kostas.papathanassiou@dlr.de).

Color versions of one or more of the figures in this paper are available online at http://ieeexplore.ieee.org.

Digital Object Identifier 10.1109/TGRS.2013.2255880 and ice sheet motion, and measurement of "bare earth" topography under dense vegetation, thus benefiting from the large penetration depth of P-band radiation [3].

Many detrimental effects of the ionosphere on SAR imaging are enhanced at lower frequencies [4]-[7]. However, because the BIOMASS SAR bandwidth is limited to an International Telecommunication Union allocation of only $6 \mathrm{MHz}$, the most significant effects are differential group delays (principally affecting interferometry), Faraday rotation (affecting the balance of the polarization channels) [8], [9], and ionospheric scintillation, which is the focus of this paper. Scintillation arises from electromagnetic scattering by electron density irregularities in the ionosphere, which cause phase fluctuations across the synthetic aperture. This corrupts the radar's impulse response function (IRF), leading to coarser resolution, increased sidelobe levels, reduction in the intensity of the main-lobe peak, and random geometric shifts of the peak. Due to the small bandwidth available to BIOMASS, the impacts of scintillation principally affect the azimuthal IRF. Scintillation can also introduce different phase perturbations into repeatpass images, thus reducing interferometric coherence.

There have been several recent studies of the effects of scintillation on low-frequency SAR. Snoeij et al. [10] examined a P-band BioSAR concept similar to BIOMASS and simulated the probabilities of increases in the integrated sidelobe ratios (ISLRs), concluding that scintillation would be negligible for a dawn-dusk orbit except in the high-latitude regions, and that image shifts due to scintillation would also be negligible. Hallberg [11] investigated Faraday rotation and scintillation for three levels of ionospheric disturbance on simulated space-based SAR data formed by corrupting airborne P-band SAR data, and found that, despite reductions in image contrast caused by scintillation, it would still be possible to distinguish three classes of boreal forest (clear-cut, young, and mature) assuming a "moderately disturbed" ionosphere. Scintillation simulators have also been developed for spaceborne SAR images based on the thin-phase screen ionospheric model introduced in [12]. For example, Rogers and Cannon [13] presented a model of wide-bandwidth simulations of 2-D (range and azimuth) IRFs for a range of parameters of the ionospheric turbulence spectrum, whilst Belcher and Rogers [14] showed how the mean resolution and azimuthal sidelobe levels of IRFs for a P-band SAR similar to BIOMASS could be modelled analytically using the same parameters that define the ionospheric irregularity spectrum.

Studies of ionospheric corruption of L-band SAR have been largely based on images from the Phased Array 


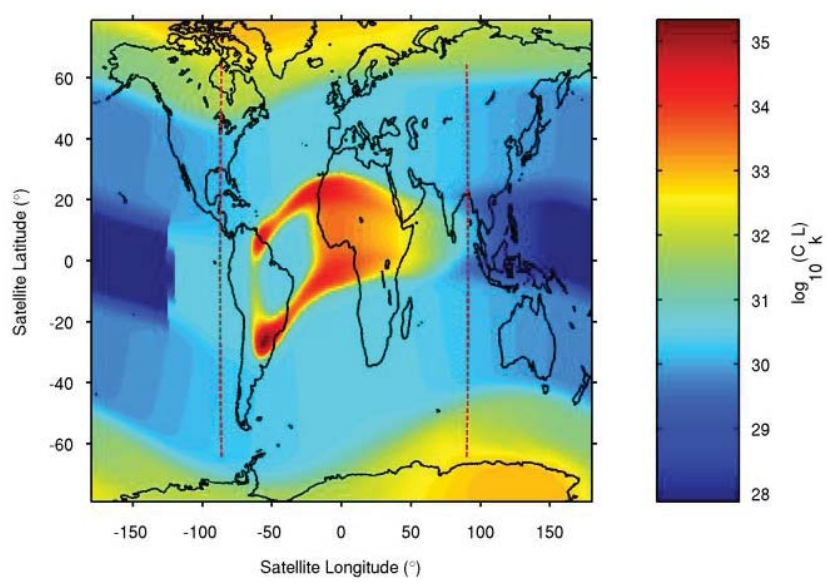

Fig. 1. WBMOD predictions of the 90th percentile of $C_{k} L$ at 00:00 UT on March 20 (so, local midnight is in the center of the image) with median sunspot number $\mathrm{R}_{z} 12=63$ and geomagnetic index $\mathrm{K}_{p}=2$. Dashed lines represent the solar terminators.

L-Band SAR (PALSAR) of the Advanced Land Observing Satellite [15]. Carrano et al. [16] demonstrated how a 2-D ionospheric phase screen could be constructed to reproduce the azimuthal "streaking" effect observed in PALSAR images, whilst Chapin et al. [17] presented probability distributions for ISLR, peak sidelobe ratio (PSLR), azimuth resolution, and azimuth shifts for PALSAR images based on GPS phase scintillation measurements in Alaska at the peak of the sunspot cycle.

The global morphology of scintillation has been the subject of many previous studies (reviewed in [18] and [19]) leading to the development of climatological models, such as the wideband model (WBMOD) [20] and the global ionospheric scintillation model [21]. An example of the WBMOD predictions of the vertically integrated strength of turbulence parameter $C_{k} L$ is presented in Fig. 1 for a fixed universal time (UT) of 00:00. It can be seen that scintillation principally occurs in the postsunset equatorial zone and the high-latitude auroral zones. At the equator, WBMOD indicates a sharp transition to intense turbulence at around 19:40 local time (Fig. 2). To avoid this equatorial region, a dawn-dusk orbit with a descending node at 18:00 local time is proposed for BIOMASS. However, high-latitude effects cannot be avoided; these extend farthest south in the American sector, because the north magnetic pole $\left(81^{\circ} \mathrm{N}, 110^{\circ} \mathrm{W}\right.$ in 2000$)$ is offset from the geographic pole and lies in this sector (Fig. 1).

In this paper, we quantify the effects of scintillation on BIOMASS SAR performance over the full range of solar and geophysical conditions, mainly in the context of forest observations. The mean background ionosphere (which causes substantial Faraday rotation) and large-scale gradients in the total electron content (TEC) are not included in the analysis [4], [5], [9], [22]-[25].

The effects of scintillation are considered only in the azimuthal direction and perturbations in range are neglected. Range effects include range shifts, range spreading (defocusing), and increased range sidelobes due to ionospheric turbulence (scintillation). At the BIOMASS frequency of

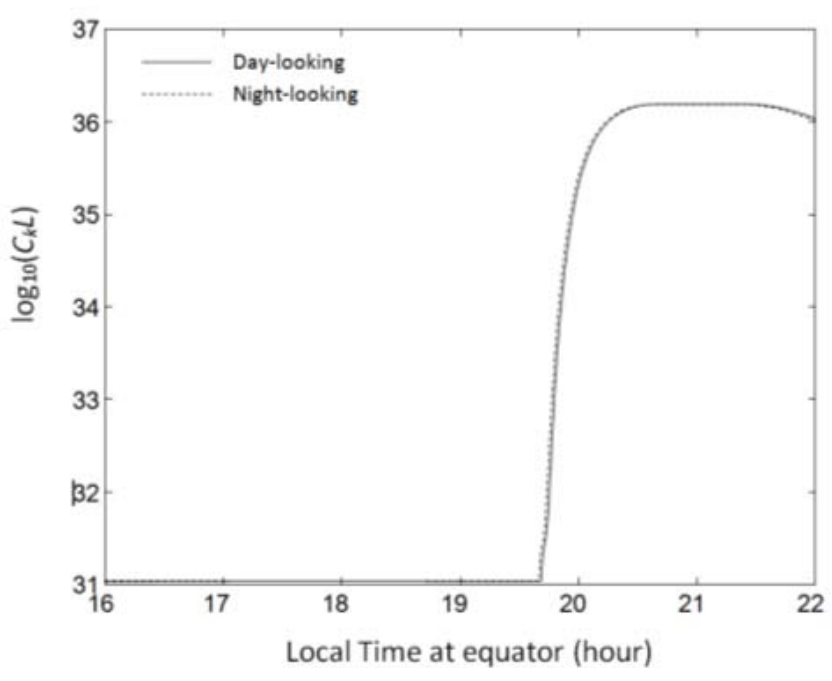

Fig. 2. WBMOD predictions of $\log _{10}\left(C_{k} L\right)$ at an equatorial location $\left(115^{\circ} \mathrm{E}, 2^{\circ} \mathrm{S}\right)$ on the dusk side as a function of the local time of the descending node. The dashed and solid lines are for a night-looking and day-looking SAR with $25^{\circ}$ look angle, respectively, and are nearly indistinguishable.

$435 \mathrm{MHz}$, excess group delay in the ionosphere leads to an increase in the radar range of $2.1 \mathrm{~m}$ per TEC Unit of slant TEC $\left(1 \mathrm{TECU}=10^{16}\right.$ electrons $\left./ \mathrm{m}\right)$. This compares with a range resolution of $25 \mathrm{~m}$ (using the full 6-MHz bandwidth) and could amount to a few pixels shift between pairs of images used for interferometry. The variation of range shifts within each image will be much smaller (dependent on range gradients in TEC and the range extent of the swath) and, as noted by Belcher and Rogers [14, p. 545], such variations could significantly increase the range sidelobes if they were to exceed one range resolution cell. For BIOMASS, this would require TEC variations greater than 11.7 TECU across the synthetic aperture, which is highly improbable. Since the range shift is inversely proportional to frequency squared, a range spreading of $0.06 \mathrm{~m}$ per TECU will occur across the $432-438 \mathrm{MHz}$ band, and this is negligible compared with the 25-m range resolution under all ionospheric conditions.

\section{Methodology}

\section{A. Overview}

Scintillations and their effects on SAR images are random phenomena that can only be described statistically. The key quantity needed is the power spectrum of the spatial variation in ionospheric electron density, whose climatology is described by WBMOD [20] as a function of location, time of day, day in the year, 12-month smoothed international sunspot number or Zürich number $R_{z} 12$, and the geomagnetic activity index $K_{p}$. In WBMOD, $C_{k} L$ is given at a specified percentile of probability for the given set of geophysical conditions. This, together with the predictions of the spectral index and outer scale size, define a log-log linear power spectrum of irregularities.

From the power spectrum, it is possible to construct random realizations of the disturbed ionosphere and the associated phase screens, which are maps of the phase perturbations imposed on a propagating wave by the nonuniform ionosphere. 
These phase screens depend on the geometry and frequency of the SAR system [26].

Each phase screen gives rise to random phase perturbations along the synthetic aperture which, if uncorrected, will cause corruption of the IRF. For repeat-pass interferometry, scintillations will also introduce decorrelation, since images acquired at different times will be affected by different phase screens.

By constructing many phase screen realizations, it is possible to learn about the statistical characteristics of the corrupted SAR measurements, and this is the basis of this paper. The four principal stages in the IRF analysis are:

1) invoke WBMOD to determine parameters of the irregularity spectrum and geomagnetic field geometry for a range of ground locations, geophysical conditions, and SAR geometries. (Note: WBMOD incorporates the coefficients of the International Geomagnetic Reference Field (IGRF) [27] for the year 2000);

2) for each configuration, construct a set of random ionospheric phase screens whose phase spectra are derived from the WBMOD parameters;

3) calculate the associated set of IRFs;

4) determine the statistics of a set of parameters ("performance metrics") that characterize the radiometric, geometric, and spatial resolution properties of the IRFs for each configuration.

For coherence analysis, we generate pairs of images corrupted by independent random 2-D phase screens.

\section{B. Quantifying the Level of Scintillation Using WBMOD}

Small-scale electron density fluctuations in the turbulent ionosphere may be modeled by a 3-D spectral density function of form

$$
Q(q)=C_{s} q^{-(2 v+1)}
$$

where $q$ is the spatial wavenumber in any given direction, $C_{s}$ defines the strength of turbulence, and $v$ is the spectral index. WBMOD produces a derived parameter $C_{k} L$, which is the strength of turbulence at the $1-\mathrm{km}$ scale integrated across the turbulent medium of thickness $L$, and is related to $C_{S}$ by the expression [29]

$$
C_{s} \times L=C_{k} L\left(\frac{2 \pi}{1000}\right)^{2 v+1} .
$$

Its value may vary over several orders of magnitude, depending on the location and geophysical conditions. Its value at a given location and time is provided by WBMOD at user-specified percentiles of the cumulative distribution function (CDF), given a user-defined $K_{p}$ (which takes the values $0-9), R_{z} 12$, and other geophysical parameters. In addition, WBMOD gives the axial ratios and orientations of the ionospheric irregularities relative to the geomagnetic field, the gradient of the electron density turbulence spectrum, and the outer scale of irregularities.

Whereas $R_{z} 12$ is strongly correlated with the solar cycle, $K_{p}$ is effectively random and shows almost no dependence on the solar cycle, as illustrated by Fig. 3, which plots the mean daily $K_{p}$ values against the sunspot number. When calculating

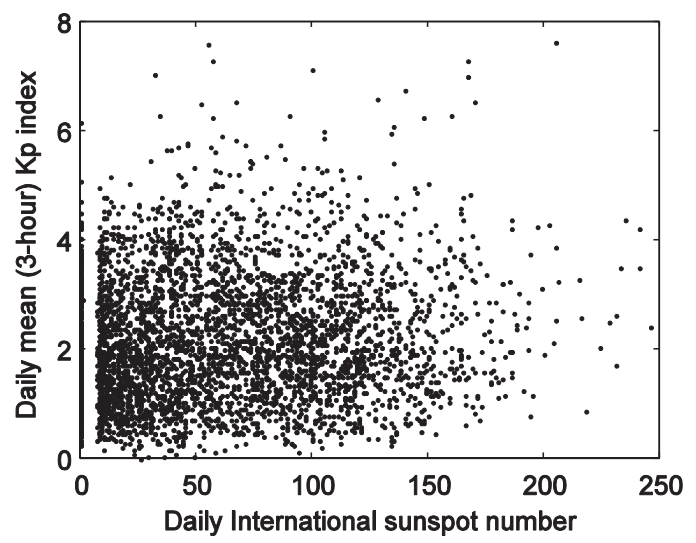

Fig. 3. Daily mean $\mathrm{K}_{p}$ index versus daily sunspot number for the period 1 January 1995 to 31 December 2005.

TABLE I

GeOPHYSICAL PARAMETERS

\begin{tabular}{ll}
\hline \hline \multicolumn{1}{c}{ PARAMETER } & \multicolumn{1}{c}{ Value } \\
\hline Dates & $\begin{array}{l}\text { 20 Mar.; 21 Jun.; 22 Sep.; } \\
\text { 21 Dec. } \\
\text { 22, 63, 106 (quartiles for } \\
\text { solar cycles 20-23) } \\
\text { dawn, dusk }\end{array}$ \\
$\begin{array}{l}\text { Local time sectors } \\
\begin{array}{l}\text { Ionospheric phase screen } \\
\text { altitude }\end{array}\end{array}$ & $350 \mathrm{~km}$ \\
$\begin{array}{l}\text { Outer scale size of } \\
\text { irregularities }\end{array}$ & $10 \mathrm{~km}$ \\
\hline \hline
\end{tabular}

the performance statistics, it is therefore better to form the unconditioned $\mathrm{CDF}$ of $C_{k} L$ by integrating out the dependence on $K_{p}$, that is, setting $C=\log \left(C_{k} L\right)$, then

$$
\begin{aligned}
P(C<c) & =\int_{-\infty}^{c} P(C) d C \\
& =\int_{K p=0}^{9} P\left(C<c \mid K_{p}\right) P\left(K_{p}\right) d K_{p} .
\end{aligned}
$$

Here

$P\left(C<c \mid K_{p}\right)=\int_{-\infty}^{c} P\left(C \mid K_{p}\right) d C$

is the CDF of $C_{k} L$ calculated for a given fixed $K_{p}$, which is easily derived from the WBMOD outputs. The probability density function (PDF) of $K_{p}, P\left(K_{p}\right)$, is derived from observations over a complete solar cycle (1995-2005).

The parameters $C_{k} L$ and $v$ were determined using WBMOD, together with $a$ and $b$, the principal and secondary elongation factors of the geomagnetic field-aligned irregularities, respectively, and parameters defining the geomagnetic field direction and its angle to the radar boresight at the ionospheric piercing point. All these parameters were generated for a grid of ground locations, for the equinoxes and solstices, and for three values of $R_{z} 12$ representing the median and quartile values for solar cycles 20-23 (see Table I). The baseline orbit and SAR parameters are given in Table II. For each given date and specification of dawn side or dusk side, a unique UT was determined for each latitude and longitude. 
TABLE II

BIOMASS ORBIT AND SAR CONFIGURATION

\begin{tabular}{ll}
\hline \hline \multicolumn{1}{c}{ Parameter } & \multicolumn{1}{c}{ Value } \\
\hline Satellite altitude & $650 \mathrm{~km}$ \\
Orbit inclination & $98^{\circ}$ (sun-synchronous) \\
Local time of ascending node & $06: 00$ \\
SAR look angle & $25^{\circ}$ from nadir (left or right) \\
Squint angle (azimuth) & $0^{\circ}$ \\
Radio wavelength, $\lambda$ & $0.689 \mathrm{~m}$ \\
Antenna aperture (along track), $d_{a}$ & $12 \mathrm{~m}$ \\
\hline \hline
\end{tabular}

\section{Generation of Ionospheric Phase Screens}

Approximating the medium by a thin phase screen at 350-km altitude (as used in WBMOD), the spatial autocorrelation function of the 2-D phase screen may be represented by the function [12, eq. (12)]

$$
R_{\phi}(y)=r_{e}^{2} \lambda^{2} G \sec (\theta) C_{s} L\left|\frac{y}{2 q_{0}}\right|^{\nu-1 / 2} \frac{K_{\nu-1 / 2}\left(q_{0} y\right)}{2 \pi \Gamma(v+1 / 2)}
$$

where $r_{e}$ is the classical electron radius, $\lambda$ is the radio wavelength, $K$ is a modified Bessel function of the second kind, $\Gamma$ is Euler's gamma function, and $q_{0}$ is the smallest wavenumber (or "outer scale") of the turbulence spectrum.

$$
G=\frac{a b}{\cos \theta \sqrt{A C-B^{2} / 4}}
$$

is a geometric "enhancement factor" $(\geq 1) ; \theta$ is the acute angle between the propagation vector and the vertical; and $A, B$, and $C$ are the anisotropy factors [28, eq. (41)] dependent on $a, b$, and the direction of propagation relative to the geomagnetic field. The argument $y$ is given by

$$
y=\sqrt{\frac{C \Delta \rho_{x}^{2}-B \Delta \rho_{x} \Delta \rho_{y}+A \Delta \rho_{y}^{2}}{A C-B^{2} / 4}}
$$

where $\Delta \rho_{x}$ and $\Delta \rho_{y}$ are the spatial separations along the screen aligned to geomagnetic north and east, respectively.

A 2-D phase screen aligned to the SAR in the along-track and cross-track directions may be produced by interpolation from a phase screen generated in the geomagnetic coordinates with the autocorrelation function in (5). However, when large numbers of azimuthal IRF realizations are required, it is computationally more efficient to generate $1-\mathrm{D}$ phase screens in the azimuth direction only.

The correlation between two points on a line aligned along azimuth that subtends an angle $\gamma$ to geomagnetic north is given by

$$
R_{\phi}(l)=r_{e}^{2} \lambda^{2} G \sec \theta C_{s} L\left|\frac{\alpha l}{2 q_{0}}\right|^{\nu-1 / 2} \frac{K_{\nu-1 / 2}\left(q_{0} \alpha l\right)}{2 \pi \Gamma(v+1 / 2)}
$$

where $l$ is the separation distance in azimuth and

$$
\alpha=\left[\frac{A \cos ^{2} \gamma-B \cos \gamma \sin \gamma+C \sin ^{2} \gamma}{A C-B^{2} / 4}\right]^{1 / 2} .
$$

Taking the Fourier transform yields the 1-D azimuthal phase power spectrum

$$
\Phi_{1 D}(q)=\frac{r_{e}^{2} \lambda^{2} G L \sec \theta C_{s} \Gamma(v)}{2 \pi^{1 / 2} \Gamma(v+1 / 2)} \frac{\alpha^{2 \nu-1}}{\left(q^{2}+\alpha^{2} q_{0}^{2}\right)^{v}} .
$$

For each set of geophysical and geometrical conditions, a set of 100 random ionospheric phase screens was generated, each with an azimuth extent of $22.6 \mathrm{~km}$ at $350-\mathrm{km}$ altitude. This represents the maximum single-look synthetic aperture at ionospheric heights for a 12-m antenna as determined from the expression

where $\lambda$ is the radio wavelength, $d_{a}$ is the physical antenna aperture, and $R_{\text {iono }}$ is the cross-track slant range from the phase screen to the ground. Each phase screen realization was constructed by filtering a random number sequence with zero mean and unit variance by the phase spectrum (following [30]). The phase was then doubled to account for two-way propagation through the phase screen (assuming perfect correlation on the up and down paths through the ionosphere). This assumes that the ionosphere remains stationary and constant during the formation of the synthetic aperture (i.e., the velocity of ionospheric drift is negligible compared with the spacecraft velocity). Identical random number sequences were used to generate each complete set of 100 phase screens to ensure that any variations in the derived statistics could be attributed solely to the changes in the spectral parameters of the phase and not to the random variations.

To simplify the analysis, the high-frequency "ray optics" approximation was used to describe radio propagation through the phase screens, which neglects the effects of diffraction by small-scale ionospheric perturbations. Sample simulations (not shown) of a planar $435-\mathrm{MHz}$ wave propagated $350 \mathrm{~km}$ beyond a phase screen using the split-step parabolic equation method [13], [14], [16], [30] exhibited mean absolute differences in phase (compared with the ray optics method) of less than 0.1 radians for $C_{k} L$ values up to $10^{34}$ (an extreme value-see statistics in of [7, Fig. 6]) and using a typical phase spectral index of $2 v=2.5$ and other parameters as simulated by WBMOD for a test location at $110^{\circ} \mathrm{W}, 0^{\circ} \mathrm{N}$. Since this figure is negligible in comparison with the standard deviation (SD) of the phase in the screen, the approximation of ray optics should not significantly change the IRFs derived below.

\section{Generation of Impulse Response Functions}

The single-look IRF was calculated as [26]

$$
G_{\text {Single-look }}(d)=\left|\sum_{n=-N / 2}^{N / 2} \exp \left(i\left(\frac{4 \pi n \alpha d}{R \lambda}+\phi_{n}\right)\right)\right|^{2}
$$

$$
D_{\text {iono }}=\frac{R_{\text {iono }} \lambda}{d_{a}}
$$

where $d$ is the IRF azimuthal distance on the ground, $\alpha$ is the pulse repetition distance, $R$ is the range from satellite 


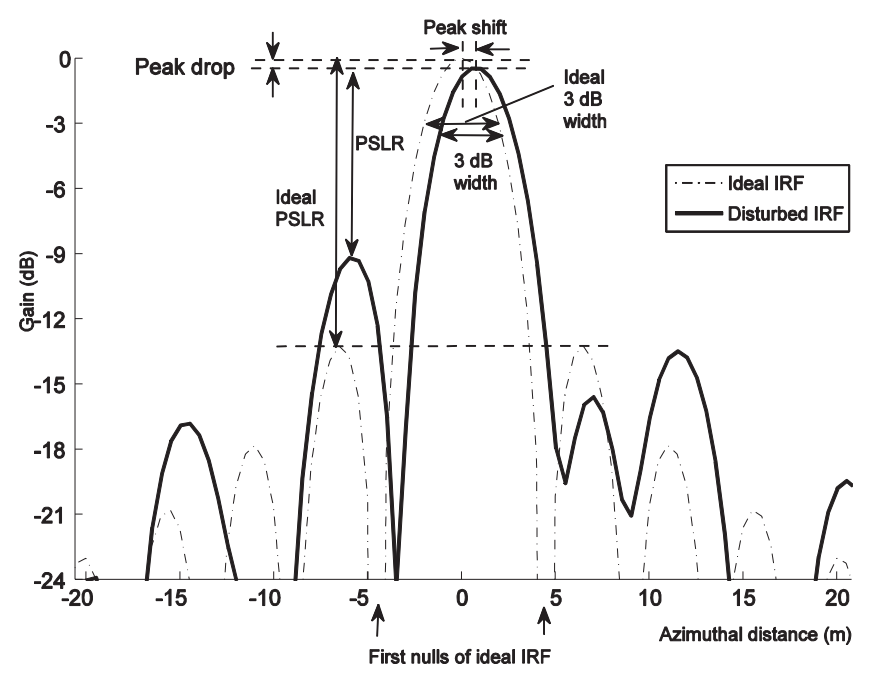

Fig. 4. Metrics determined from the IRF (dashed line = ideal IRF, solid line $=$ phase-corrupted IRF).

to ground when normal to the track, and $\phi_{n}$ is the phase in the azimuth phase screen. An ideal reference IRF was also calculated by setting the phases $\phi_{n}$ to zero. No aperture weighting or physical antenna gain weighting was applied, but would normally be used to improve the sidelobe levels. The IRFs were generated for ground sampling distances $d$, spanning $\pm 120 \mathrm{~m}$ at $0.5-\mathrm{m}$ intervals. This generates 25 or 26 sidelobes on either side of the central peak of the ideal IRF, all of which were used in calculating the performance metrics.

For four-look SAR processing, IRFs were generated for contiguous quarter length apertures and incoherently averaged, that is,

$G_{4-\text { look }}(d)=\frac{1}{4} \sum_{m=0}^{3}\left|\sum_{n=(m-2) N / 4}^{(m-1) N / 4} \exp \left(i\left(\frac{4 \pi n \alpha d}{R \lambda}+\phi_{n}\right)\right)\right|^{2}$

and calculated over the same range of ground distances $d$.

\section{E. Determination of IRF Metrics}

An example of the central part of an ideal and phasecorrupted IRF is given in Fig. 4, illustrating the measurement of the main-lobe peak, 3-dB width, PSLR, reduction in peak gain ("peak drop"), and peak shift.

The performance metrics used to characterize the quality of the IRF are defined as follows.

1) Geometric distortion and point target radiometric error are characterized by the IRF main-lobe peak shift (offset from zero) and peak drop, measured at the highest local maximum in the IRF. The height and shift are determined by fitting a parabola to the three points around the maximum of the sampled IRF.

2) The spread in energy is characterized by ISLR, given by the ratio between the integrated energy in the sidelobes and the energy in the main lobe (defined by the first nulls of the ideal IRF). A trapezoidal integration method is used.

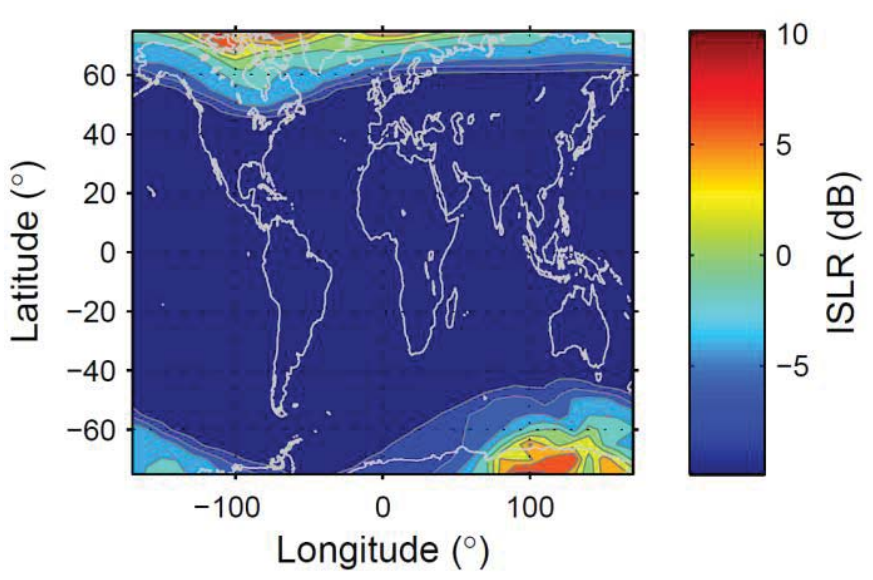

Fig. 5. Mean single-look ISLR at the 90th percentile of $C_{k} L$ on the dusk side for March equinox, at median sunspot number. The ideal ISLR is $-9.9 \mathrm{~dB}$.

3) Potential ambiguities are described by PSLR, which is the ratio of the height of the maximum sidelobe to the peak of the main lobe of the disturbed IRF. The latter is calculated as in (1), whilst the peak sidelobe level is determined as the highest point outside the first nulls of the disturbed IRF.

4) Changes in resolution are measured by the increase in the 3-dB width, which is the percentage increase in the width of the main lobe at half the peak height, determined by linear interpolation.

The mean, SD, and maximum and minimum values of each metric were recorded at each location for each combination of geophysical and SAR parameters.

\section{RESULTS}

\section{A. Impact of Scintillation on Impulse Response Functions}

Fig. 5 presents a global map of the mean single-look ISLR under median sunspot conditions at dusk for the March equinox. It can be thought of as representing the effects of scintillations over a 24-h period during which the Earth rotates beneath the satellite. Clearly, scintillation causes no significant increase in the ISLR above its ideal value of $-9.9 \mathrm{~dB}$ except at high latitudes. A similar picture emerges for all the IRF metrics, confirming that a dawn-dusk orbit removes scintillation effects at the equator. The longitudinal asymmetry at high latitudes is due to the offset of the geomagnetic poles, causing locations in the North American sector to be at higher geomagnetic latitudes than elsewhere. Scintillations can occur over a substantial part of the Alaskan and Canadian boreal forests.

Comparison with Fig. 6, which maps the percentage tree cover derived from the MODIS Vegetation Continuous Fields product [32], indicates that boreal forests in the Eurasian sector would encounter much weaker scintillation than forests in North America, since they lie at lower geomagnetic latitudes. Fig. 6 shows that the majority of Eurasian forests lie below $60^{\circ} \mathrm{N}$ geomagnetic, but North American forests occur up to the $70^{\circ} \mathrm{N}$ geomagnetic latitude contour.

The effect of this longitudinal asymmetry is even clearer in Fig. 7, which presents the dusk-side ISLR at the 90th 


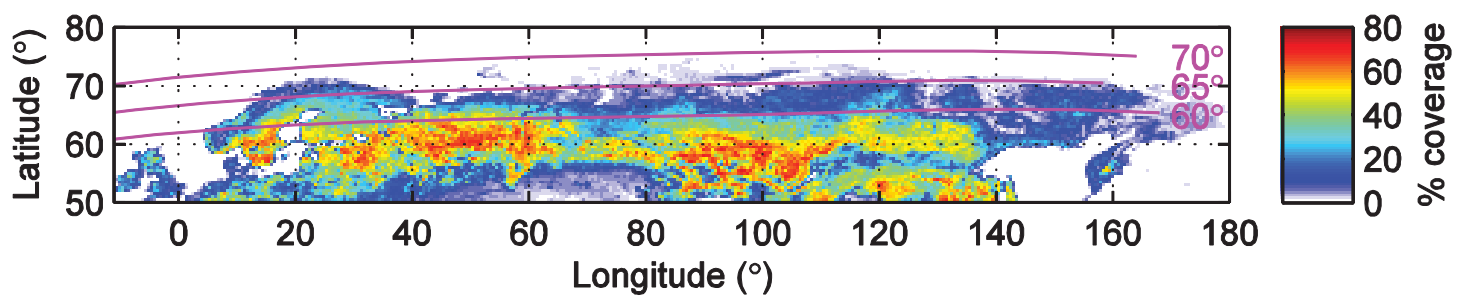

a)

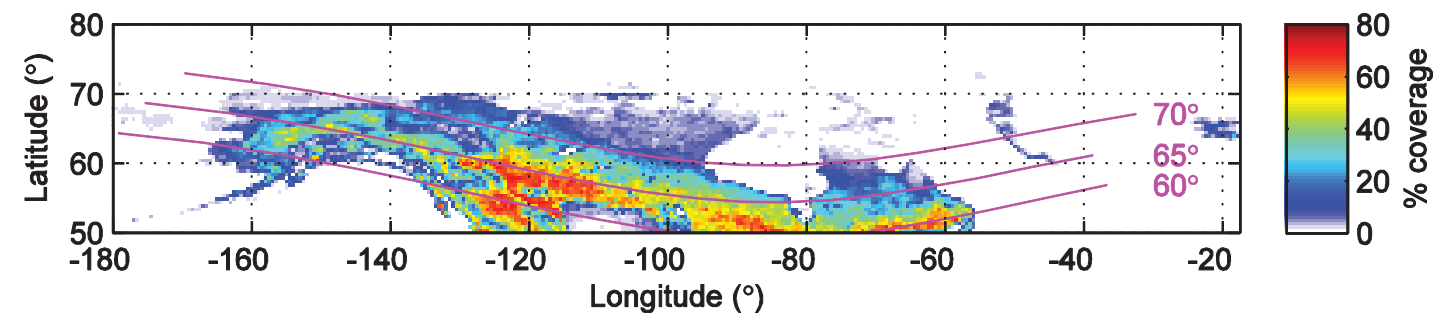

Fig. 6. Tree cover in (a) Eurasia and (b) North America. (Data source: NASA MODIS VCF product.) Contours represent corrected geomagnetic latitudes [31] for epoch 2000 at 350-km altitude. (Data source: NASA Goddard Space Flight Centre - Omniweb.)
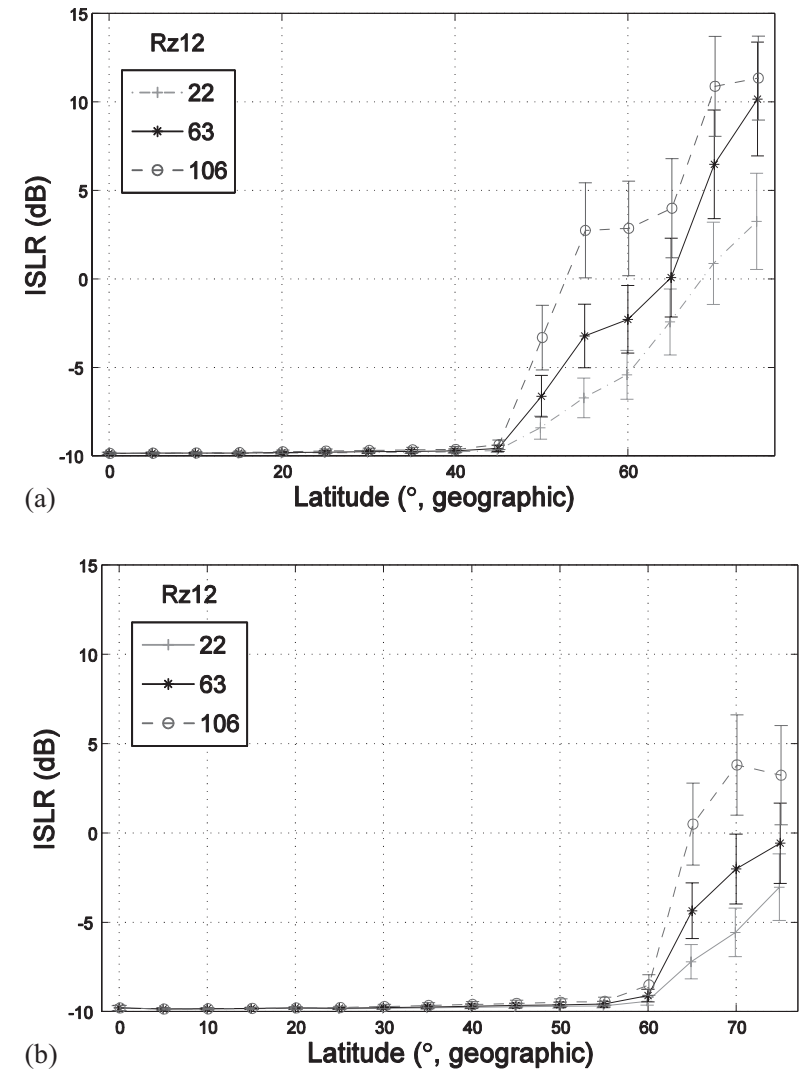

Fig. 7. Mean ISLR at the 90th percentile $C_{k} L$ for quartiles of $\mathrm{R}_{z} 12$ at (a) $110^{\circ} \mathrm{W}$ and (b) $100^{\circ} \mathrm{E}$. Error bars indicate $\pm 1 \mathrm{SD}$.

percentile of $C_{k} L$ along two geographic meridians: 1) $110^{\circ} \mathrm{W}$, passing through the Canadian boreal forest and 2) $100^{\circ} \mathrm{E}$, which corresponds to a cut through the central Siberian forests. The magnetic pole lies at $110^{\circ} \mathrm{W}$ such that scintillations will extend to much lower geographic latitudes in the Canadian sector, and this figure emphasizes the importance of this longitudinal difference for forest observations. The three lines in each panel show the mean ISLR for the three quartile sunspot numbers for the last four solar cycles; error bars represent $\pm 1 \mathrm{SD}$ and outlier points are the minimum and
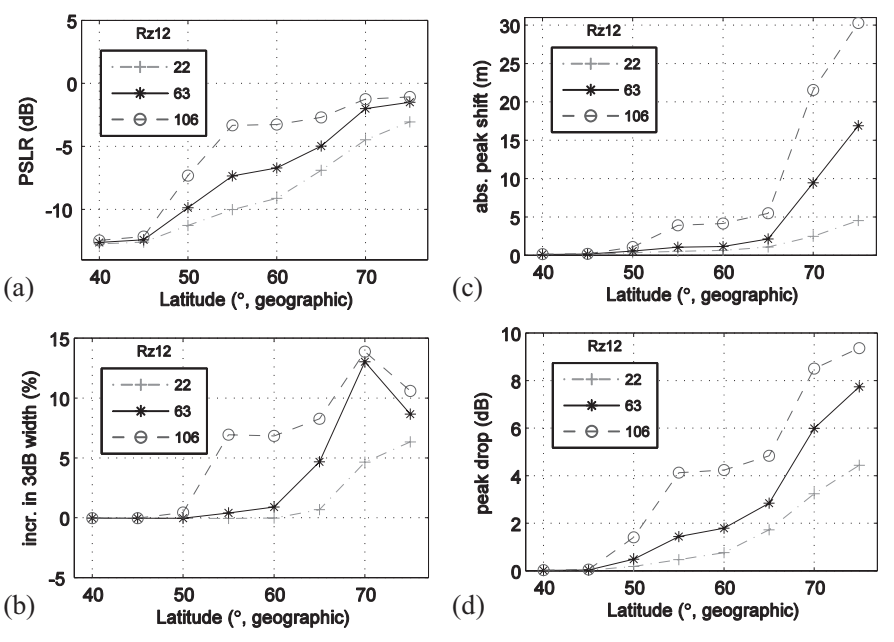

Fig. 8. Mean values of single-look IRF metrics at the 90th percentile of $C_{k} L$ for quartiles of $R_{z} 12$ at $110^{\circ}$ W. (a) PSLR. (b) Increase in 3-dB main-lobe width. (c) Absolute peak shift. (d) Peak drop.

maximum values for each set of 100 simulations. At $110^{\circ} \mathrm{W}$, the effects of scintillations are negligible south of $45^{\circ} \mathrm{N}$, while the equivalent limit at $100^{\circ} \mathrm{E}$ is $60^{\circ} \mathrm{N}$. Hence, in Eurasia, scintillations have little impact on the BIOMASS's primary objective of monitoring forests, affecting only the region of low-density tree coverage between $60^{\circ} \mathrm{N}$ and the northern tree line at approximately $70^{\circ} \mathrm{N}$. However, in North America they will affect a significant part of the northernmost temperate and boreal forests, particularly, near sunspot maximum.

Plots of the other IRF performance metrics over the range $40^{\circ} \mathrm{N}-75^{\circ} \mathrm{N}$ for the $110^{\circ} \mathrm{W}$ meridian (i.e., in the "worst-case" longitude sector) are presented in Fig. 8(a)-(d), with means and SDs of all metrics given in Table III. In each figure, the sample statistics are presented for the 90th percentile of $C_{k} L$, so they represent disturbance levels exceeded only one day in ten. All metrics clearly exhibit greater corruption of the IRF under higher solar activity.

PSLR [Fig. 8(a)] provides a measure of the spread of energy around a point scatter in images containing separated 
TABLE III

Single-Look IRF Metrics: $110^{\circ} \mathrm{W}$ Meridian, 90Th Percentile of $C_{k}$ L 20 MARCh, Right-LOOKING SAR, DUSK SIDE

\begin{tabular}{|c|c|c|c|c|c|c|c|c|}
\hline \multirow[t]{2}{*}{$R_{\mathbf{Z}} 12$} & \multicolumn{8}{|c|}{ Latitude $\left({ }^{\circ} \mathrm{N}\right)$} \\
\hline & 40 & 45 & 50 & 55 & 60 & 65 & 70 & 75 \\
\hline & \multicolumn{8}{|c|}{ ISLR $(\mathrm{dB})$ Ideal Value $=-9.9 \mathrm{~dB}$} \\
\hline & \multicolumn{8}{|l|}{ Mean } \\
\hline 22 & -9.8 & -9.7 & -8.4 & -6.7 & -5.4 & -2.4 & 0.9 & 3.2 \\
\hline 63 & -9.7 & -9.6 & -6.6 & -3.2 & -2.3 & 0.1 & 6.5 & 10.2 \\
\hline \multirow[t]{2}{*}{106} & -9.6 & -9.4 & -3.3 & 2.7 & 2.8 & 4.0 & 10.9 & 11.3 \\
\hline & \multicolumn{8}{|c|}{ Standard deviation } \\
\hline 22 & 0.07 & 0.11 & 0.65 & 1.12 & 1.38 & 1.86 & 2.32 & 2.71 \\
\hline 63 & 0.10 & 0.17 & 1.17 & 1.80 & 1.91 & 2.22 & 3.07 & 3.22 \\
\hline \multirow[t]{3}{*}{106} & 0.15 & 0.27 & 1.83 & 2.68 & 2.66 & 2.79 & 2.82 & 2.36 \\
\hline & \multicolumn{8}{|c|}{ PSLR $(\mathrm{dB})$ Ideal Value $=-13.3 \mathrm{~dB}$} \\
\hline & \multicolumn{8}{|l|}{ Mean } \\
\hline 22 & -12.7 & -12.6 & -11.3 & -10.0 & -9.1 & -6.9 & -4.5 & -3.1 \\
\hline 63 & -12.6 & -12.4 & -9.9 & -7.3 & -6.7 & -5.0 & -2.0 & -1.5 \\
\hline \multirow[t]{2}{*}{106} & -12.5 & -12.1 & -7.3 & -3.3 & -3.3 & -2.7 & -1.2 & -1.1 \\
\hline & \multicolumn{8}{|c|}{ Standard deviation } \\
\hline 22 & 0.38 & 0.47 & 1.21 & 1.72 & 2.02 & 2.54 & 2.55 & 2.21 \\
\hline 63 & 40 & & 78 & 2.50 & 2.58 & 2.70 & 1.81 & 1.40 \\
\hline \multirow[t]{3}{*}{106} & 0.55 & 0.74 & 2.52 & 2.25 & 2.25 & 2.10 & 1.07 & 0.94 \\
\hline & \multirow{2}{*}{\multicolumn{8}{|c|}{$\begin{array}{l}\text { Increase in 3-dB Width (\%) (Ideal Width }=5.3 \mathrm{~m} \text { ) } \\
\text { ean }\end{array}$}} \\
\hline & & & & & & & & \\
\hline 22 & 0.0 & 0.0 & 0.0 & 0.0 & 0.0 & 0.7 & 4.6 & 6.3 \\
\hline 63 & 0.0 & 0.0 & 0.0 & 0.4 & 0.9 & 4.7 & 13 & 8.7 \\
\hline \multirow[t]{2}{*}{106} & 0.0 & 0.0 & 0.4 & 6.9 & 6.8 & 8.3 & 13.9 & 10.6 \\
\hline & \multicolumn{8}{|c|}{ Standard deviation } \\
\hline 22 & 0.03 & 0.05 & 0.36 & 0.97 & 1.66 & 4.9 & 20.33 & 26.17 \\
\hline 63 & 0.04 & 0.07 & 1.03 & 3.68 & 5.77 & 20.35 & 38.26 & 24.61 \\
\hline \multirow[t]{3}{*}{106} & 0.06 & 0.11 & 3.69 & 28.40 & 28.66 & 27.12 & 37.38 & 33.02 \\
\hline & \multicolumn{8}{|c|}{ Absolute Peak Shift (m) } \\
\hline & \multicolumn{8}{|l|}{ Mean } \\
\hline 22 & 0.1 & 0.1 & 0.3 & 0.5 & 0.6 & 1.1 & 2.5 & 4.5 \\
\hline 63 & 0.1 & 0.2 & 0.6 & 1.1 & 1.1 & 2.1 & 9.5 & 16.9 \\
\hline \multirow[t]{2}{*}{106} & 0.1 & 0.2 & 1.1 & 3.9 & 4.2 & 5.5 & 21.5 & 30.3 \\
\hline & \multicolumn{8}{|c|}{ Standard deviation } \\
\hline 22 & 0.07 & 0.09 & 0.24 & 0.37 & 0.45 & 1.16 & 3.33 & 5.18 \\
\hline 63 & 0.08 & 0.11 & 0.39 & 1.15 & 1.16 & 3.03 & 7.66 & 12.48 \\
\hline \multirow[t]{3}{*}{106} & 0.10 & 0.14 & 1.15 & 4.50 & 4.82 & 5.87 & 15.08 & 20.68 \\
\hline & & & Absol & te Peak & Drop & (dB) & & \\
\hline & Mean & & & & & & & \\
\hline 22 & 0.0 & 0.0 & 0.2 & 0.5 & 0.8 & 1.7 & 3.2 & 4.4 \\
\hline 63 & 0.0 & 0.0 & 0.5 & 1.4 & 1.8 & 2.8 & 6.0 & 7.7 \\
\hline 106 & 0.0 & 0.1 & 1.4 & 4.1 & 4.2 & 4.8 & 8.5 & 9.4 \\
\hline & Standar & d deviat & & & & & & \\
\hline 22 & 0.01 & 0.01 & 0.10 & 0.24 & 0.38 & 0.77 & 1.22 & 1.39 \\
\hline 63 & 0.01 & 0.02 & 0.26 & 0.69 & 0.81 & 1.15 & 1.44 & 1.26 \\
\hline 106 & 0.02 & 0.03 & 0.70 & 1.34 & 1.37 & 1.42 & 1.11 & 1.13 \\
\hline
\end{tabular}

distinct scatterers, and is strongly dependent on the aperture weighting function. Raised PSLR in SAR images can lead to false target detection or the obscuration of nearby weaker scatterers. The statistics of PSLR may be interpreted relative to a threshold at which autofocusing algorithms would be expected to perform well in the presence of distinct scatterers. For example, the PSLR expected at the 90th percentile remains

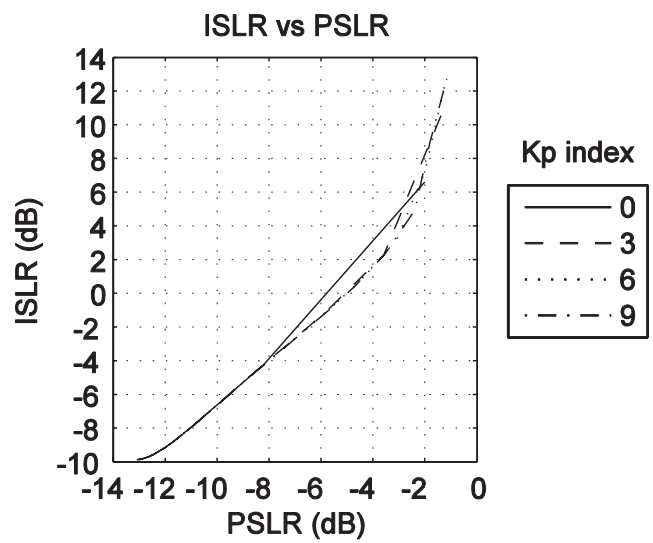

Fig. 9. Mean dusk-side ISLR versus mean PSLR at $\left(60^{\circ} \mathrm{N}, 110^{\circ} \mathrm{W}\right)$ on 20 March 2000 for median sunspot number and with $\mathrm{K}_{p}=0,3$, 6, and 9 .

below a threshold of $-5 \mathrm{~dB}$ up to $60^{\circ} \mathrm{N}$ (or $50^{\circ} \mathrm{N}-55^{\circ} \mathrm{N}$ under higher sunspot conditions), but tends toward a maximum of $0 \mathrm{~dB}$ at the highest latitudes.

Up to the northern tree line and with $90 \%$ confidence interval, the mean 3-dB resolution [Fig. 8(b)] increases by less than $10 \%$ above its ideal value of $5.3 \mathrm{~m}$, although variation can be up to $35 \%$ at $1 \mathrm{SD}$ above the mean. The mean peak shift [Fig. 8(c)] increases by up to $2 \mathrm{~m}$ at low to median sunspot number and up to $5 \mathrm{~m}$ under high sunspot numbers. (At higher latitudes, these values increase by tens of meters, perhaps as a result of misidentification of a sidelobe as the main lobe.) Mean peak drop [Fig. 8(d)] will be less than $3 \mathrm{~dB}$ for low to median sunspot conditions, increasing to $5 \mathrm{~dB}$ at high sunspot levels. This will affect the radiometric accuracy of the SAR data, with consequences for calibration, if any calibration sites are located at high latitudes (see [33]).

ISLR combines the effects of all sidelobes into a measure of energy spread. This makes it a particularly useful indicator of image quality for BIOMASS, since increases in ISLR cause reduced contrast and reduced ability to distinguish gradients in biomass, such as those occur under deforestation or forest degradation; examples of these effects are shown in Section III-C. However, ISLR is strongly related to the properties of point scatterers, as shown in Fig. 9, which is a plot of the mean dusk-side values of ISLR against PSLR at $\left(60^{\circ} \mathrm{N}, 110^{\circ} \mathrm{W}\right)$. This plot was calculated by varying the $C_{k} L$ percentiles from $0 \%$ to $100 \%$ in steps of $5 \%$ for four values of $K_{p}$. There is a strong linear correlation between the two metrics, with ISLR $(\mathrm{dB}) \approx 7+1.4 \times$ PSLR $(\mathrm{dB})$, except under near-ideal, low $C_{k} L$ conditions, where ISLR rises more slowly with increasing PSLR; above a value of $-3 \mathrm{~dB}$, PSLR begins to saturate as it approaches its maximum of $0 \mathrm{~dB}$.

There is little seasonal variation in any of the IRF metrics except at latitudes exceeding $70^{\circ} \mathrm{N}$, where, because continuous solar illumination in summer smoothes out ionospheric irregularities, performance against all metrics is better in summer than in winter. There is also little difference between dawn and dusk for latitudes below $65^{\circ} \mathrm{N}$. Above this latitude, both the mean absolute shift and the increase in mean $3-\mathrm{dB}$ resolution are larger (i.e., worse) on the dawn side, while sidelobe levels tend to be higher (worse) on the dusk side. 
TABLE IV

Four-LoOK IRF MetriCS: $110^{\circ} \mathrm{W}$ MERIDIAN, 90Th PERCENTILE OF $C_{k} L 20$ MARCH, Right-LOOKING SAR, DUSK SIDE

\begin{tabular}{|c|c|c|c|c|c|c|c|c|}
\hline \multirow[t]{2}{*}{$R_{\mathbf{Z}} 12$} & \multicolumn{8}{|c|}{ Latitude $\left({ }^{\circ} \mathrm{N}\right)$} \\
\hline & 40 & 45 & 50 & 55 & 60 & 65 & 70 & 75 \\
\hline & \multicolumn{8}{|c|}{ ISLR $(\mathrm{dB})$ Ideal Value $=-10.7 \mathrm{~dB}$} \\
\hline & \multicolumn{8}{|l|}{ Mean } \\
\hline 22 & -10.7 & -10.6 & -10.2 & -9.4 & -8.6 & -6.8 & -4.5 & -3.1 \\
\hline 63 & -10.6 & -10.6 & -9.4 & -7.4 & -6.7 & -5.1 & -0.9 & 1.8 \\
\hline \multirow[t]{2}{*}{106} & -10.6 & -10.5 & -7.6 & -3.5 & -3.4 & -2.5 & 2.9 & 3.9 \\
\hline & \multicolumn{8}{|c|}{ Standard deviation } \\
\hline 22 & 0.01 & 0.02 & 0.16 & 0.36 & 0.52 & 0.83 & 1.07 & 1.18 \\
\hline 63 & 0.02 & 0.03 & 0.37 & 0.75 & 0.84 & 1.02 & 1.27 & 1.35 \\
\hline \multirow[t]{3}{*}{106} & 0.03 & 0.05 & 0.73 & 1.16 & 1.17 & 1.21 & 1.38 & 1.36 \\
\hline & \multicolumn{8}{|c|}{ PSLR (dB) Ideal Value $=-13.3 \mathrm{~dB}$} \\
\hline & \multicolumn{8}{|l|}{ Mean } \\
\hline 22 & -13.1 & -13.0 & -12.4 & -11.7 & -11.2 & -10.2 & -8.3 & -6.4 \\
\hline 63 & -13.0 & -13.0 & -11.7 & -10.6 & -10.4 & -9.1 & -3.8 & -1.9 \\
\hline \multirow[t]{2}{*}{106} & -13.0 & -12.8 & -10.8 & -6.9 & -6.6 & -5.7 & -1.5 & -1.1 \\
\hline & \multicolumn{8}{|c|}{ Standard deviation } \\
\hline 22 & 0.12 & 0.16 & 0.45 & 0.72 & 1.04 & 2.18 & 2.8 & 2.83 \\
\hline 63 & 0.14 & 0.20 & 0.72 & 1.89 & 2.25 & 2.55 & 2.55 & 1.43 \\
\hline \multirow[t]{3}{*}{106} & 0.17 & 0.25 & 1.91 & 2.86 & 2.70 & 2.82 & 1.25 & 1.00 \\
\hline & \multicolumn{8}{|c|}{ Increase in $3-\mathrm{dB}$ width $(\%)$ (Ideal Width $=21.2 \mathrm{~m})$} \\
\hline & \multicolumn{8}{|l|}{ Mean } \\
\hline 22 & 0.1 & 0.1 & 1.0 & 2.8 & 4.7 & 12.1 & 30.2 & 49.9 \\
\hline 63 & 0.1 & 0.2 & 2.9 & 9.8 & 12.8 & 24.4 & 85.5 & 93.4 \\
\hline \multirow[t]{2}{*}{106} & 0.2 & 0.3 & 9.7 & 45.0 & 45.8 & 58.9 & 90.5 & 107.4 \\
\hline & \multicolumn{8}{|c|}{ Standard deviation } \\
\hline 22 & 0.06 & 0.10 & 0.90 & 2.45 & 4.18 & 10.76 & 30.16 & 43.74 \\
\hline 63 & 0.09 & 0.17 & 2.63 & 8.66 & 11.47 & 23.92 & 73.17 & 89.55 \\
\hline \multirow[t]{3}{*}{106} & 0.14 & 0.28 & 8.58 & 40.9 & 41.58 & 49.69 & 98.45 & 98.74 \\
\hline & \multicolumn{8}{|c|}{ Absolute Peak Shift (m) } \\
\hline & \multicolumn{8}{|l|}{ Mean } \\
\hline 22 & 0.1 & 0.2 & 0.5 & 0.9 & 1.1 & 1.8 & 3.0 & 4.9 \\
\hline 63 & 0.2 & 0.2 & 0.9 & 1.6 & 1.8 & 2.6 & 7.7 & 14.4 \\
\hline \multirow[t]{2}{*}{106} & 0.2 & 0.3 & 1.6 & 4.6 & 4.6 & 5.5 & 17.4 & 24.0 \\
\hline & \multicolumn{8}{|c|}{ Standard deviation } \\
\hline 22 & 0.11 & 0.14 & 0.41 & 0.65 & 0.82 & 1.35 & 2.44 & 4.18 \\
\hline 63 & 0.13 & 0.18 & 0.67 & 1.21 & 1.40 & 2.06 & 6.17 & 10.37 \\
\hline 106 & 0.16 & 0.23 & 1.21 & 3.87 & 3.93 & 4.74 & 12.84 & 15.93 \\
\hline & & & Abso & lute Pea & Drop & dB) & & \\
\hline & Mean & & & & & & & \\
\hline 22 & 0.0 & 0.0 & 0.1 & 0.3 & 0.5 & 1.1 & 2.1 & 2.9 \\
\hline 63 & 0.0 & 0.0 & 0.3 & 0.9 & 1.1 & 1.8 & 4.1 & 5.6 \\
\hline 106 & 0.0 & 0.0 & 0.9 & 2.7 & 2.7 & 3.2 & 6.3 & 7.2 \\
\hline & Standar & d devia & & & & & & \\
\hline 22 & 0.00 & 0.01 & 0.05 & 0.13 & 0.21 & 0.42 & 0.69 & 0.82 \\
\hline 63 & 0.01 & 0.01 & 0.14 & 0.36 & 0.43 & 0.63 & 0.95 & 0.92 \\
\hline 106 & 0.01 & 0.02 & 0.35 & 0.79 & 0.80 & 0.85 & 0.89 & 0.86 \\
\hline
\end{tabular}

Finally, although changing from a right-looking to a leftlooking SAR beam shifts the ionospheric piercing point by approximately $300 \mathrm{~km}$, this has very little effect on $C_{k} L$ (as shown in Fig. 2) or the mean values of the IRF metrics.

1) Multilook Processing: The IRF performance metrics presented above are for an along-track SAR aperture equal
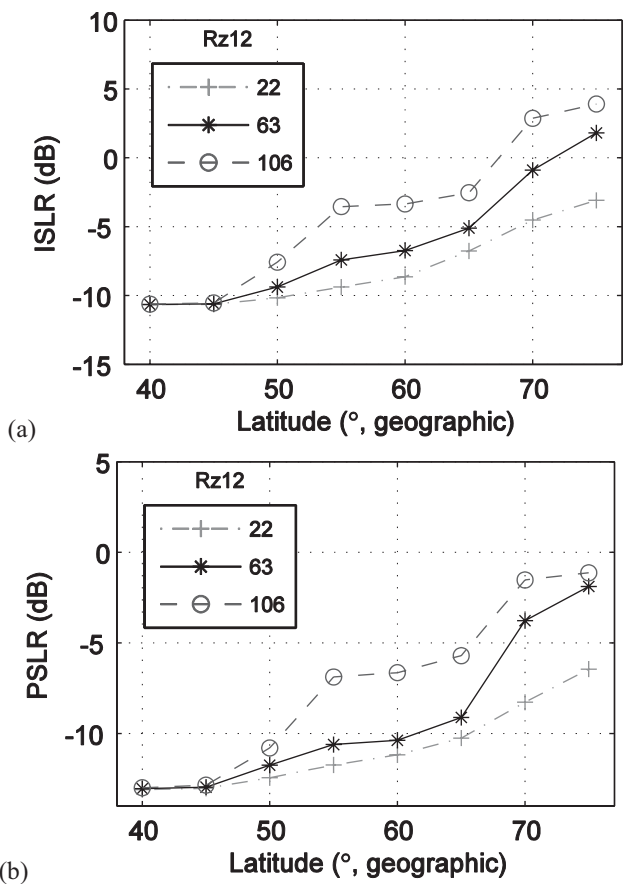

(b)
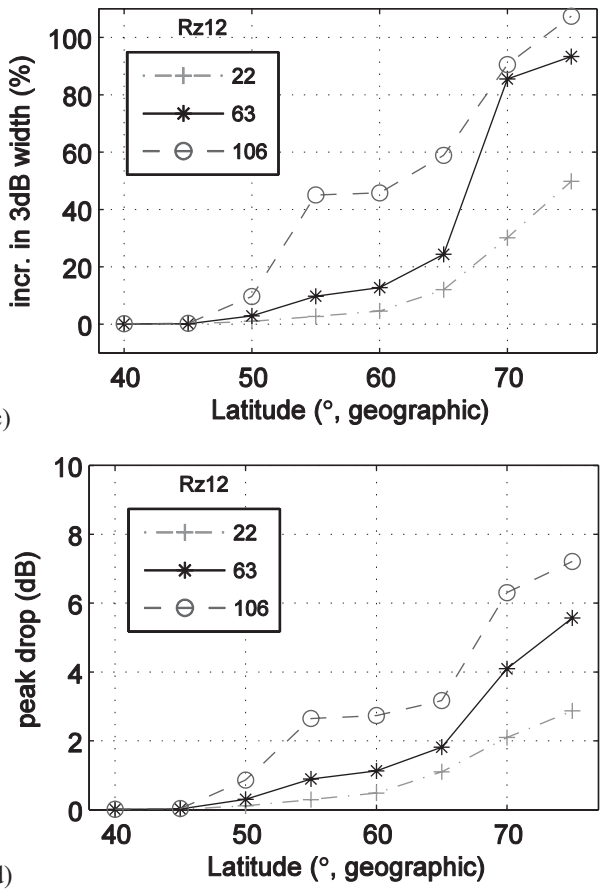

Fig. 10. IRF metric statistics in the same format as Fig. 8 but produced using four-look processing. (a) ISLR. (b) PSLR. (c) Percentage increase in 3-dB main-lobe width. (d) Peak drop.

to the 3-dB beamwidth, which projects to $22.6 \mathrm{~km}$ at the assumed height of the ionospheric phase screen $(350 \mathrm{~km})$. However, the variance of the phase screens diminishes at scales below an outer scale length of $10 \mathrm{~km}$, so if the signal is processed with more than two subapertures, the phase variance across the aperture is reduced and the sidelobe levels are also reduced (improve), although at the expense of the resolution.

Statistics of four-look IRF metrics are given in Table IV and are presented in Fig. 10 for the same conditions as for 


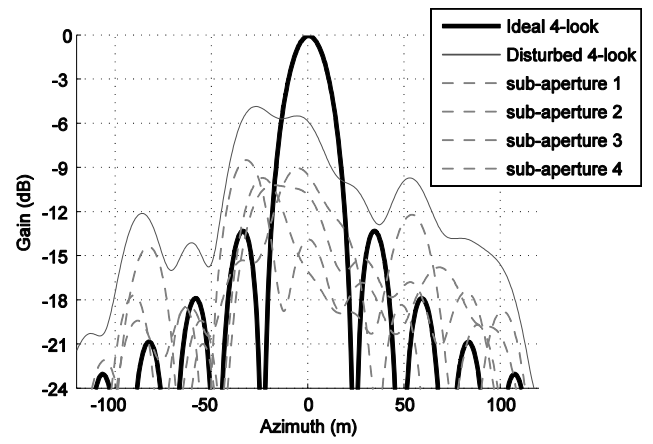

Fig. 11. Example of the disturbed four-look IRF (solid thin line) and its component subaperture IRFs (dashed lines) calculated at $\left(70^{\circ} \mathrm{N}, 110^{\circ} \mathrm{W}\right)$, dusk side for the 90 th percentile of $C_{k} L$ with $\mathrm{R}_{z} 12=62.8$. The ideal fourlook IRF is also shown (thick line).
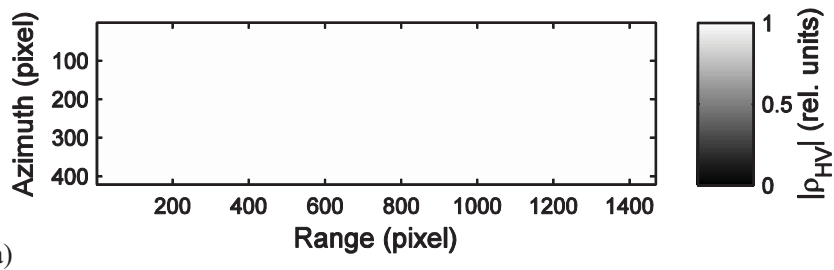

(a)

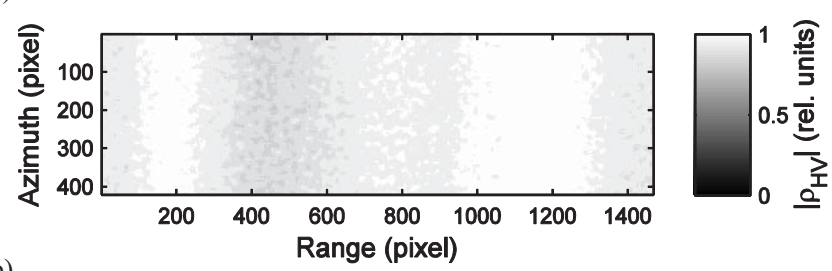

(b)

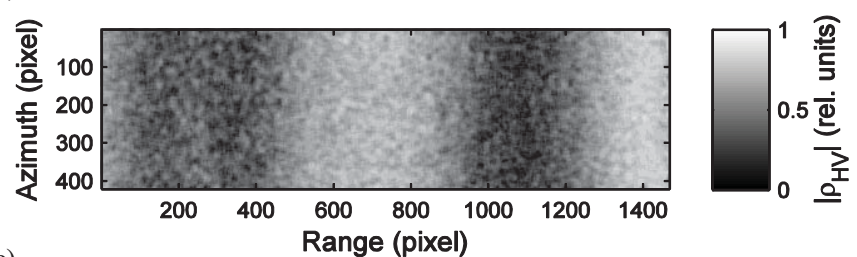

(c)

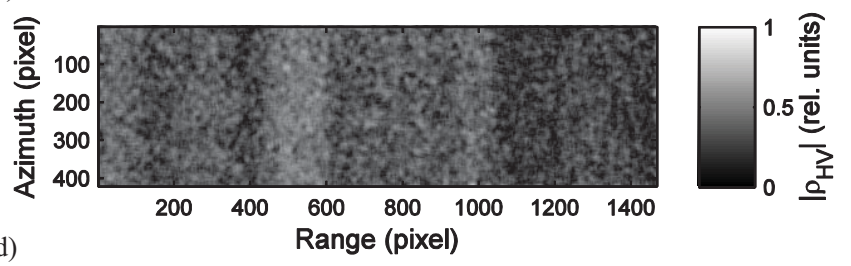

Fig. 12. Coherence between HV image pairs for a uniform scene corrupted by independent ionospheric phase screens at (a) $40^{\circ} \mathrm{N}$, (b) $50^{\circ} \mathrm{N}$, (c) $60^{\circ} \mathrm{N}$ and (d) $70^{\circ} \mathrm{N}$ for the 90th percentile of $\mathrm{CkL}$ at median sunspot number and at the March equinox.

the single-look IRF metrics in Figs. 7(a) and 8. At $60^{\circ} \mathrm{N}$, the ISLR is improved by 3-6 dB [compare Fig. 10(a) with Fig. 7(a)] and PSLR improves by 3-4 dB [compare Fig. 10(b) with Fig. 8(a)]. The mean peak drop is around two-thirds (in decibels) of that for full-aperture processing at all latitudes, while the mean absolute peak shift is nearly unchanged (not shown).

However, the mean percentage increase (degradation) in along-track resolution is substantially larger for four-look than for single-look processing [compare Fig. 10(c) with Fig. 8(b) and Tables III and IV], and can exceed $100 \%$ (i.e., the 3-dB resolution is doubled from its ideal value of $21.2 \mathrm{~m}$ ) at $75^{\circ} \mathrm{N}$ under high sunspot conditions. This is caused by different random shifts in the subaperture IRFs that are incoherently averaged (as illustrated by the example for $70^{\circ} \mathrm{N}$ shown in Fig. 11).

For IRFs formed from a single subaperture (i.e., no averaging), the resolution increase is within a few percentages of that for the single-look full-beam aperture, although the mean absolute peak shift is approximately 1-3 m greater, due to increases in the random linear phase component at smaller aperture lengths.

\section{B. Impact of Scintillation on SAR Interferometry}

Scintillation may reduce the interferometric coherence between a pair of images $M_{1}$ and $M_{2}$, where coherence is defined as

$$
|\rho|=\left|\frac{\left\langle M_{1} M_{2}^{*}\right\rangle}{\sqrt{\left\langle\left|M_{1}\right|^{2}\right\rangle\left\langle\left|M_{2}\right|^{2}\right\rangle}}\right| .
$$

Here, \langle\rangle is the expected value approximated by averaging over $16 \times 16$ pixels, and ${ }^{*}$ denotes the complex conjugate.

To simulate this, a scene corresponding to a uniform distributed target (boreal forest with a uniform biomass of $200 \mathrm{t} / \mathrm{ha}$ ) was simulated using the BIOMASS end-to-end Simulator (BEES) [34]. Pairs of 2-D ionospheric phase screen realizations were then produced using WBMOD phase spectrum parameters appropriate to a BIOMASS satellite on the dusk side at $110^{\circ} \mathrm{W}$ for latitudes between $40^{\circ} \mathrm{N}$ and $75^{\circ} \mathrm{N}$ for the 90th percentile of $C_{k} L$, at median geomagnetic activity $\left(K_{p}=2\right)$, median sunspot number, and at the March equinox. For each pair of phase screens, a corresponding pair of images was produced in the HV polarimetric channel using the BEES simulator, which applies the ionospheric phase shifts to the image using the technique of Scheiber et al. [35, p. 943]. In practice, some temporal decorrelation of the scene would occur between image acquisitions, but this is not simulated here, and the only difference between each pair of simulated images is the seed value that initializes the random number generator used to generate the ionospheric phase screen realizations.

Fig. 12 presents the corresponding HV coherences, $\left|\rho_{\mathrm{HV}}\right|$, at four different latitudes. The correlation in coherence values in the azimuth (vertical) direction, indicated by the broad vertical bands, occurs because neighboring pixels in azimuth are derived from azimuth phase profiles differing only at the edges of the synthetic aperture; variations in range instead exhibit spatial variation corresponding to that in the phase screen.

The mean values of $\left|\rho_{\mathrm{HV}}\right|$ across the scene for three different combinations of random number generator seed values and two random realizations of the forest scene distribution are shown as a function of latitude in Fig. 13 and tabulated, with SDs, in Table V. For clarity, values corresponding to each combination of the scene and the random number sequence used to produce the phase screens are joined by lines; the set joined by the thick solid line includes the four image pairs used in Fig. 12. Scintillations are seen to have negligible effect on coherence 


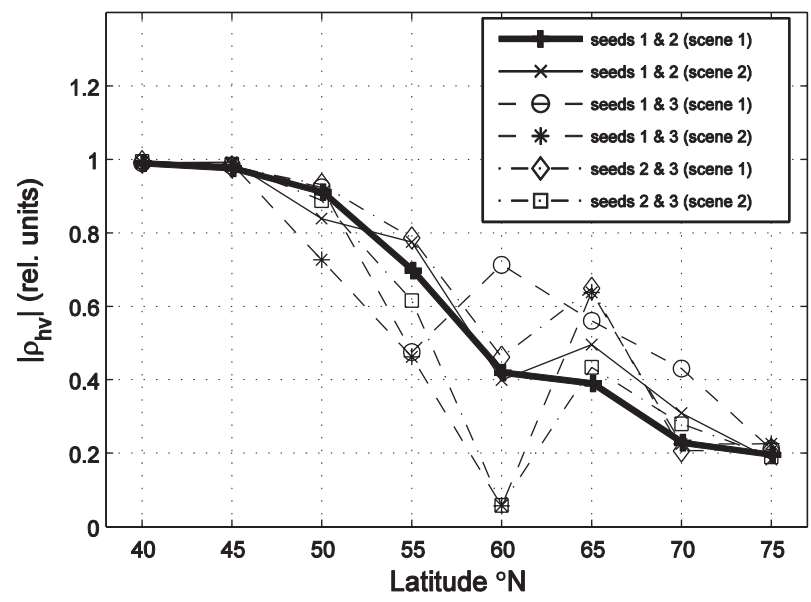

Fig. 13. Mean coherence for pairs of HV images corrupted by ionospheric scintillations. The thicker line links values calculated for the examples in Fig. 12, whilst other lines represent different combinations of independent phase screens (generated under the same geophysical conditions but with different random number sequences) for two scene realizations with the same statistical properties.

TABLE V

HV COHERENCE For All Phase SCREen Combinations

\begin{tabular}{|c|c|c|c|c|c|c|c|c|}
\hline $\begin{array}{l}\text { Lat. } \\
\left({ }^{\circ} \mathrm{N}\right)\end{array}$ & 40 & 45 & 50 & 55 & 60 & 65 & 70 & 75 \\
\hline \multicolumn{9}{|c|}{ Mean Coherence $\left|\rho_{\mathbf{H V}}\right|$} \\
\hline \multicolumn{9}{|c|}{ Scene 1} \\
\hline $\begin{array}{l}\text { Seed } \\
1 \& 2\end{array}$ & 0.99 & 0.98 & 0.91 & 0.70 & 0.42 & 0.39 & 0.23 & 0.20 \\
\hline $\begin{array}{l}\text { Seed } \\
1 \& 3\end{array}$ & 0.99 & 0.98 & 0.92 & 0.47 & 0.71 & 0.56 & 0.43 & 0.21 \\
\hline $\begin{array}{l}\text { Seed } \\
2 \& 3\end{array}$ & 0.99 & 0.98 & 0.93 & 0.79 & 0.46 & 0.65 & 0.21 & 0.21 \\
\hline \multicolumn{9}{|c|}{ Scene 2} \\
\hline $\begin{array}{l}\text { Seed } \\
1 \& 2\end{array}$ & 0.99 & 0.99 & 0.84 & 0.78 & 0.40 & 0.50 & 0.31 & 0.18 \\
\hline $\begin{array}{l}\text { Seed } \\
1 \& 3\end{array}$ & 0.99 & 0.99 & 0.73 & 0.46 & 0.06 & 0.64 & 0.22 & 0.23 \\
\hline $\begin{array}{l}\text { Seed } \\
2 \& 3\end{array}$ & 0.99 & 0.99 & 0.89 & 0.62 & 0.06 & 0.43 & 0.28 & 0.19 \\
\hline \multicolumn{9}{|c|}{ Standard Deviation of Coherence $\left|\rho_{\mathbf{H V}}\right|$} \\
\hline \multicolumn{9}{|c|}{ Scene 1} \\
\hline $\begin{array}{l}\text { Seed } \\
1 \& 2\end{array}$ & 0.01 & 0.01 & 0.05 & 0.11 & 0.20 & 0.14 & 0.10 & 0.10 \\
\hline $\begin{array}{l}\text { Seed } \\
1 \& 3\end{array}$ & 0.01 & 0.01 & 0.03 & 0.18 & 0.15 & 0.16 & 0.19 & 0.11 \\
\hline $\begin{array}{l}\text { Seed } \\
2 \& 3\end{array}$ & 0.00 & 0.01 & 0.03 & 0.10 & 0.15 & 0.06 & 0.12 & 0.10 \\
\hline \multicolumn{9}{|c|}{ Scene 2} \\
\hline $\begin{array}{l}\text { Seed } \\
1 \& 2\end{array}$ & 0.00 & 0.00 & 0.08 & 0.09 & 0.18 & 0.18 & 0.13 & 0.09 \\
\hline $\begin{array}{l}\text { Seed } \\
1 \& 3\end{array}$ & 0.01 & 0.01 & 0.11 & 0.21 & 0.03 & 0.13 & 0.10 & 0.11 \\
\hline $\begin{array}{l}\text { Seed } \\
2 \& 3\end{array}$ & 0.00 & 0.01 & 0.08 & 0.14 & 0.03 & 0.26 & 0.12 & 0.09 \\
\hline
\end{tabular}

at lower latitudes. Mean coherence above 0.8 is achieved up to $50^{\circ} \mathrm{N}$, but decreases sharply further north.

The scintillations causing the degradation in coherence also affect each separate image. This is illustrated in Fig. 14, which shows the mean single-look azimuthal ISLR as a function of

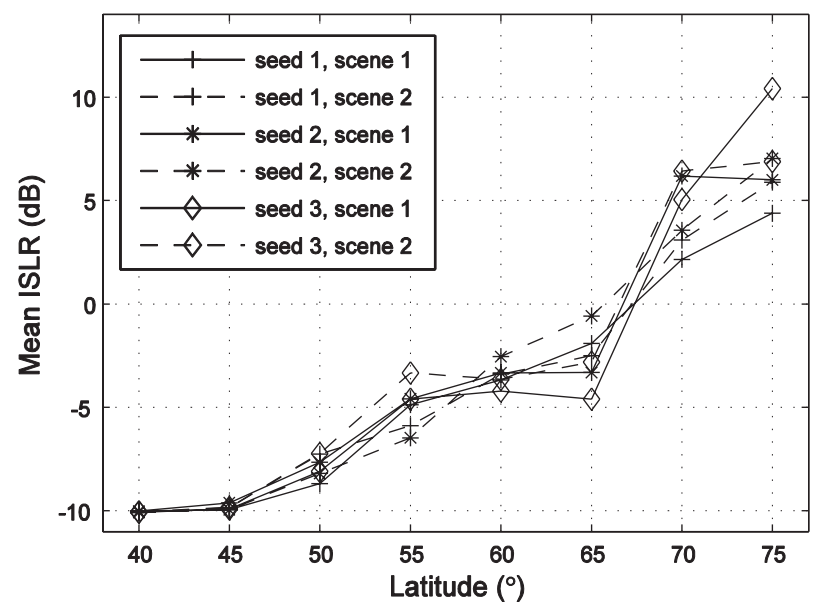

Fig. 14. Mean azimuthal ISLR versus latitude for three phase screen realizations and two scene realizations for the 90th percentile of CkL at $\mathrm{Kp}=2$, median sunspot number, and at the March equinox.

latitude, calculated over the six phase screens (three random number generator seed values for each of the two scenes). These values are tabulated with their SDs in Table VI. The ISLR statistics are based on the central azimuth line of the phase screen (variation with azimuth is insignificant).

Fig. 15 plots the mean azimuthal ISLR (decibels) (including values from both phase screens) against the HV coherence. The coherence falls by around 0.06 per decibel of ISLR for ISLR less than around $-2 \mathrm{~dB}$, while for high ISLR, coherence roughly takes its minimum value. Mean coherence greater than 0.8 is generally achieved for ISLR less than around $-7 \mathrm{~dB}$, but there is considerable spread around this value. The two correlations produced with phase screen seed 3 and scene 2 at $60^{\circ} \mathrm{N}$ (Fig. 13) have coherence significantly below the trend. This indicates that single-image metrics are not a reliable guide to the quality of coherence measurements.

\section{Impact of Scintillation on SAR Image Contrast}

The effect of increasing scintillation on the information in BIOMASS images was simulated by applying ionospheric phase screens to an airborne P-band DLR E-SAR HH image obtained from the Remningstorp test site in Sweden as part of the BIOSAR-I campaign. This was modified to more closely resemble a BIOMASS image by using the method in [35] to change the azimuth and range resolutions, modify the sidelobes of the IRF, increase the noise level, and change the range and azimuth ambiguities.

The scene is dominated by forest, but with several clearings, seen as the dark regions in Fig. 16(a), which is a singlelook slant-range $\mathrm{HH}$ intensity image with no ionospheric perturbation. Fig. 16(b) presents the same image after applying a phase screen for an extremely disturbed ionosphere with $K_{p}=7$ and upper-quartile sunspot number (106). The corrupted image displays an azimuthal smearing effect with markedly reduced contrast. Infilling of the clearings occurs because the degraded IRF puts much more of its energy into the sidelobes, as evidenced by the increased ISLR of $11.0 \pm 3.7 \mathrm{~dB}$. 
TABLE VI

AZIMUthal ISLR for EACH PHASE SCREEN

\begin{tabular}{|c|c|c|c|c|c|c|c|}
\hline Lat. $\left({ }^{\circ} \mathrm{N}\right)$ & 40 & 45 & 50 & 55 & 60 & 65 & $70 \quad 75$ \\
\hline \multicolumn{8}{|c|}{ Mean ISLR (dB) } \\
\hline \multicolumn{8}{|l|}{ Scene 1} \\
\hline Seed 1 & -10.01 & -9.95 & -8.69 & -4.87 & -3.68 & -1.9 & 2.154 .39 \\
\hline Seed 2 & -10.01 & -9.62 & -7.65 & -4.60 & -3.33 & -3.32 & 6.196 .00 \\
\hline Seed 3 & -10.07 & -9.91 & -8.10 & -4.61 & -4.22 & -4.60 & 5.0610 .4 \\
\hline \multicolumn{8}{|l|}{ Scene 2} \\
\hline Seed 1 & -10.09 & -9.85 & -7.27 & -5.88 & -3.39 & -2.49 & 3.095 .89 \\
\hline Seed 2 & -10.08 & -9.95 & -8.19 & -6.48 & -2.54 & -0.57 & 3.567 .03 \\
\hline Seed 3 & -10.04 & -9.83 & -7.22 & -3.33 & -3.65 & -2.81 & 6.426 .89 \\
\hline
\end{tabular}

Standard Deviation of ISLR $(\mathrm{dB})$

Scene 1

\begin{tabular}{lccccccc} 
Seed 1 & 0.16 & 0.12 & 0.62 & 1.66 & 1.53 & 1.08 & 2.152 .66 \\
Seed 2 & 0.15 & 0.35 & 1.23 & 2.3 & 1.79 & 1.12 & 2.981 .85 \\
Seed 3 & 0.07 & 0.15 & 0.99 & 1.61 & 1.96 & 1.32 & 1.982 .64 \\
Scene 2 & & & & & & & \\
Seed 1 & 0.09 & 0.22 & 1.25 & 1.89 & 2.14 & 1.92 & 2.762 .74 \\
Seed 2 & 0.05 & 0.11 & 0.85 & 1.19 & 2.31 & 1.73 & 2.282 .97 \\
Seed 3 & 0.09 & 0.20 & 1.66 & 1.60 & 1.25 & 2.49 & 1.442 .11 \\
\hline
\end{tabular}

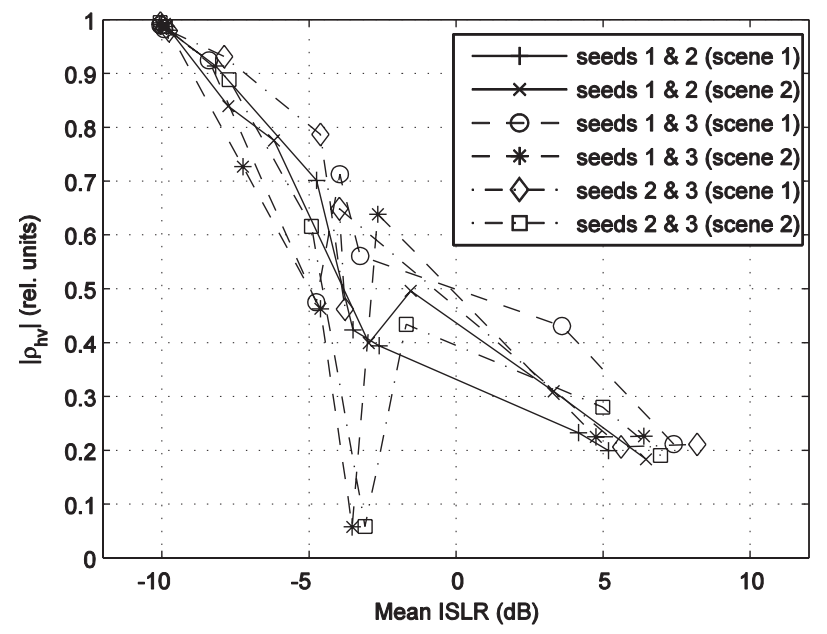

Fig. 15. Mean HV coherence versus mean ISLR in pairs of simulated BIOMASS images for the 90th percentile of $C_{k} L$ at $K_{p}=2$, median sunspot number, and at the March equinox. The mean ISLR of both images in each pair is shown.

The original scene was corrupted by three phase screens, simulated using the WBMOD model parameters appropriate to $\left(60^{\circ} \mathrm{N}, 110^{\circ} \mathrm{W}\right)$ for $K_{p}=1,3$, and $7, R_{z} 12=106$, and at the 90th percentile of $C_{k} L$, using the BIOMASS parameters shown in Table II. Transects over a high-contrast region of the ensuing images at range pixel 1170 (indicated by the vertical lines in Fig. 16) are presented in Fig. 17. Here the intensity profiles for the uncorrupted and corrupted images are marked as solid and dashed lines, respectively, and the data are averaged along the transect with a moving window of 200 pixels to reduce local variability.
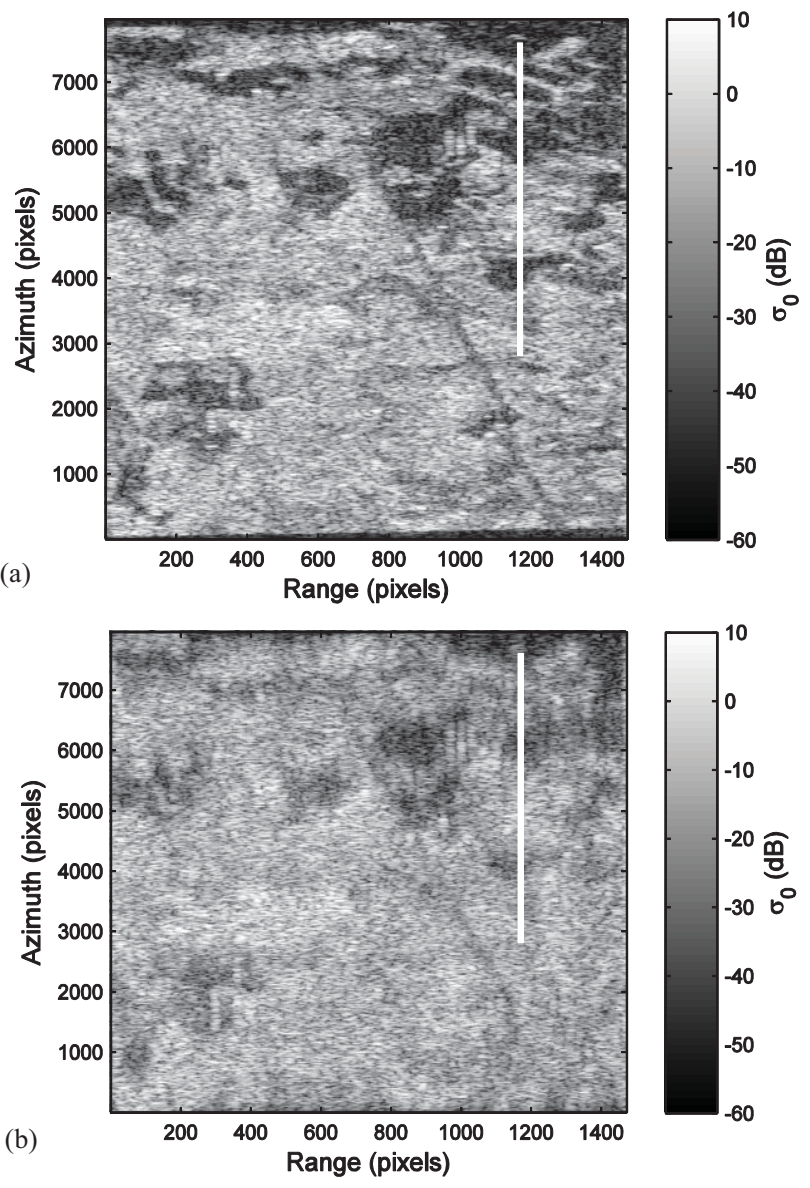

Fig. 16. HH single-look intensity images with (a) no ionospheric perturbation and (b) phase screen applied for the 90th $C_{k} L$ percentile at $\mathrm{Kp}=7, R z 12=106,60^{\circ} \mathrm{N}, 110^{\circ} \mathrm{W}$, and at dusk side. The vertical line marks a transect through a high-contrast region chosen for further analysis.

Lower levels of ionospheric disturbance [e.g., panels (a) and (b)] reduce the contrast between smaller clearings and forest, and weaken the gradients at edges, though not markedly. However, at high levels of disturbance (e.g., panel c) most of the low-intensity regions of the image increase by several decibels near a sharp intensity boundary. This behavior varies spatially (e.g., the boundary at azimuth $=5700$ is less affected than that at azimuth $=3900$ ), due to the inhomogeneous and random nature of the phase screen. Hence, uncorrected scintillation effects will hinder the extraction of information on forest boundaries and biomass, but only at high latitudes under very disturbed conditions in North America.

\section{CONCLUSION}

In this paper, we made use of the WBMOD climatological model (version 15.03) to estimate the effects of ionospheric scintillation on the BIOMASS P-band SAR. Insofar as WBMOD was accurate and complete, it was predicted that, for a dawn-dusk orbit, ionospheric scintillation will have little effect on the ability of BIOMASS to achieve its primary objectives of measuring forest biomass and height, except in the high-latitude North American sector during high solar activity. In this sector, effects on the IRF and repeat-pass coherence become noticeable from $50^{\circ} \mathrm{N}$ and 

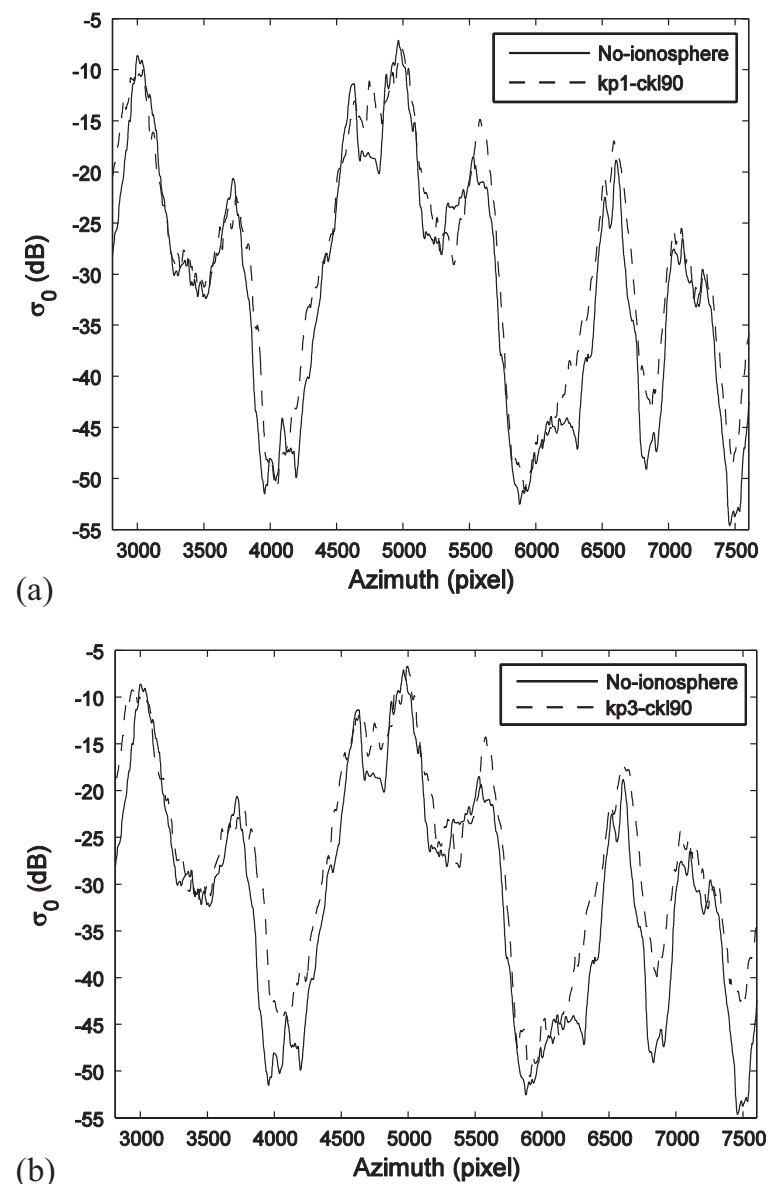

(b)

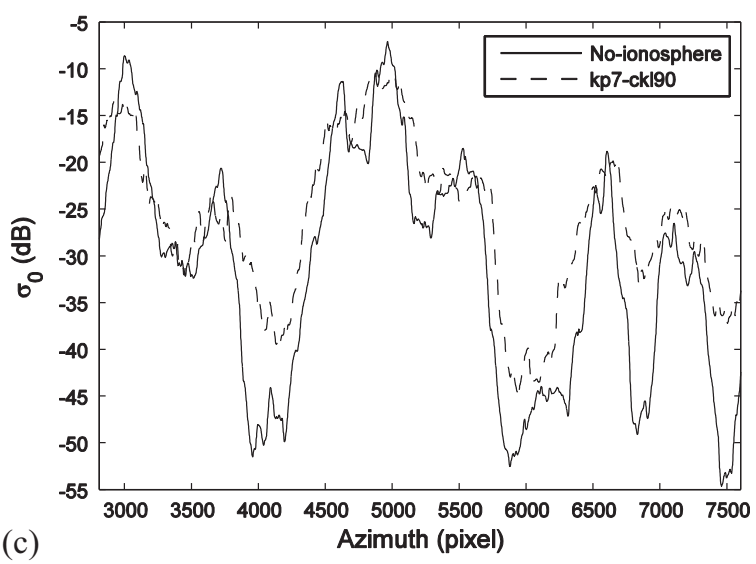

Fig. 17. HH intensity (after 200-pixel averaging) at range index 1170 for the 90th $C_{k} L$ percentile at $\mathrm{Kp}=1,3$, and 7 (panels a, b, and c, respectively). The solid and dashed lines represent uncorrupted and corrupted profiles, respectively.

increase with both latitude and solar activity. The variability about the mean also tends to increase, though not uniformly for all metrics. For high solar activity, transitions due to forest clearance or age and biomass differences between adjacent forest stands will become blurred, and regions of lower backscatter (lower biomass) may suffer artificial increases of several decibels due to energy spread caused by defocusing. These effects can be reduced by multilooking, but at the expense of reduced and spatially varying geometric fidelity.
For ice sheet monitoring, which is a secondary objective of the BIOMASS mission, severe scintillations cannot be avoided by any choice of local time for a polar orbiting satellite.

\section{ACKNOWLEDGMENT}

The authors would like to thank J. Secan and Northwest Research Associates for providing the WBMOD scintillation model.

\section{REFERENCES}

[1] H. Balzter, M. Davidson, T. Le Toan, P. Paillou, K. Papathanassiou, S. Plummer, S. Quegan, F. Rocca, S. S. Saatchi, H. Shugart, and L. M. H. Ulander, "BIOMASS report for assessment," Eur. Space Agency, Harvard Univ., Cambridge, MA, USA, Tech. Rep. ESA SP 1313/2, 2008.

[2] M. Neumann, S. S. Saatchi, L. M. H. Ulander, and J. E. S. Fransson, "Assessing performance of L-and P-band polarimetric interferometric SAR data in estimating boreal forest above-ground biomass," IEEE Trans. Geosci. Remote Sens., vol. 50, no. 3, pp. 714-726, Mar. 2012.

[3] E. J. Rignot, R. Zimmermann, and J. J. van Zyl, "Spaceborne applications of P-band imaging radars for measuring forest biomass," IEEE Trans. Geosci. Remote Sens., vol. 33, no. 5, pp. 1162-1169, Sep. 1995.

[4] Z.-W. Xu, J. Wu, and Z.-S. Wu, "Potential effects of the ionosphere on space-based SAR imaging," IEEE Trans. Antennas Propag., vol. 56, no. 7, pp. 1968-1975, Jul. 2008.

[5] A. Ishimaru, Y. Kuga, J. Liu, Y. Kim, and T. Freeman, "Ionospheric effects on synthetic aperture radar imaging at $100 \mathrm{MHz}$ to $2 \mathrm{GHz}$," Radio Sci., vol. 34, no. 1, pp. 257-268, 1999.

[6] J. Liu, Y. Kuga, A. Ishimaru, X. Pi, and A. Freeman, "Ionospheric effects on SAR imaging: A numerical study," IEEE Trans. Geosci. Remote Sens., vol. 41, no. 5, pp. 939-947, May 2003.

[7] D. P. Belcher, "Theoretical limits on SAR imposed by the ionosphere," IET Proc. Radar Sonar Navigat., vol. 2, no. 6, pp. 435-448, Dec. 2008.

[8] J. Chen and S. Quegan, "Improved estimators of Faraday rotation in spaceborne polarimetric SAR data," IEEE Geosci. Remote Sens. Lett., vol. 7, no. 4, pp. 846-850, Oct. 2010.

[9] A. Freeman, "Calibration of linearly polarized polarimetric SAR data subject to Faraday rotation," IEEE Trans. Geosci. Remote Sens., vol. 42, no. 8, pp. 1617-1624, Aug. 2004.

[10] P. Snoeij, N. van der Valk, E. Boom, and D. H. Hoekman, "Effect of the ionosphere on P-band spaceborne SAR images," in Proc. IEEE Int. Geosci. Remote Sens. Symp., vol. 1. Jul. 2001, pp. 132-134.

[11] B. Hallberg, G. Smith, A. Olofsson, and L. M. H. Ulander, "Performance simulation of spaceborne P-band SAR for global biomass retrieval," in Proc. IEEE Int. Geosci. Remote Sens. Symp., Sep. 2004 pp. 503-506.

[12] C. L. Rino, "A power law phase screen model for ionospheric scintillation: 1, Weak scatter," Radio Sci., vol. 14, no. 6, pp. 1135-1145, 1979.

[13] N. C. Rogers and P. S. Cannon, "The synthetic aperture radar transionospheric radio propagation simulator (SAR-TIRPS)," in Proc. 11th Int. Conf. Ionospheric Radio Syst. Tech., Apr. 2009, pp. 112-116.

[14] D. P. Belcher and N. C. Rogers, "Theory and simulation of ionospheric effects on synthetic aperture radars," IET Radar, Sonar, Navigat., vol. 3 , no. 5, pp. 541-551, Mar. 2009.

[15] A. Rosenqvist, M. Shimada, N. Ito, and M. Watanabe, "ALOS PALSAR: A Pathfinder mission for global-scale monitoring of the environment," IEEE Trans. Geosci. Remote Sens., vol. 45, no. 11, pp. 3307-3316, Nov. 2007.

[16] C. S. Carrano, K. M. Groves, and R. G. Caton, "Simulating the impacts of ionospheric scintillation on L band SAR image formation," Radio Sci., vol. 47, no. RS0L20, pp. 1-14, 2012.

[17] E. Chapin, S. F. Chan, B. D. Chapman, C.W. Chen, J. M. Martin, T. R. Michel, R. J. Muellerschoen, X. Pi, and P. A. Rosen, "Impact of the ionosphere on an L-band space based radar," in Proc. IEEE Conf. Radar, Apr. 2006, pp. 51-58. 
[18] J. Aarons, "Global morphology of ionospheric scintillations," Proc. IEEE, vol. 70, no. 4, pp. 360-378, Apr. 1982.

[19] A. W. Wernik, J. A. Secan, and E. J. Fremouw, "Ionospheric irregularities and scintillation," Adv. Space Res., vol. 31, no. 4, pp. 971-981, 2003.

[20] J. A. Secan, R. M. Bussey, E. J. Fremouw, and S. Basu, "High-latitude upgrade to the wideband ionospheric scintillation model," Radio Sci., vol. 32, no. 4, pp. 1567-1574, 1997.

[21] Y. Béniguel, (2011, Sep. 1). GISM Global Ionospheric Scintillation Model, Technical Manual [Online]. Available: http://www.ieea.fr/help/gism-technical.pdf

[22] J. S. Kim and K. P. Papathanassiou, "Faraday rotation estimation performance analysis," in Proc. 8th Eur. Conf. Synth. Aperture Radar, Jun. 2010, pp. 182-185.

[23] J. S. Kim, A. Danklmayer, and K. P. Papathanassiou, "Correction of ionospheric distortions in low frequency interferometric SAR data," in Proc. Int. Geosci. Remote Sens. Symp., 2011, pp. 1505-1508.

[24] F. J. Meyer and J. B. Nicoll, "Prediction, detection and correction of faraday rotation in full polarimetric L-band SAR data," IEEE Trans. Geosci. Remote Sens., vol. 46, no. 10, pp. 3076-3086, Oct. 2008.

[25] P. A. Wright, S. Quegan, N. S. Wheadon, and C. D. Hall, "Faraday rotation effects on L-band spaceborne SAR data," IEEE Trans. Geosci. Remote Sens., vol. 41, no. 12, pp. 2735-2744, Dec. 2003.

[26] S. Quegan and J. Lamont, "Ionospheric and tropospheric effects on synthetic aperture radar performance," Int. J. Remote Sens., vol. 7, no. 4, pp. 525-539, 1986.

[27] C. C. Finlay, S. Maus, C. D. Beggan, T. N. Bondar, A. Chambodut, T. A. Chernova, A. Chulliat, V. P. Golovkov, B. Hamilton, M. Hamoudi, R. Holme, G. Hulot, W. Kuang, B. Langlais, V. Lesur, F. J. Lowes, H. Lühr, S. MacMillan, M. Mandea, S. McLean, C. Manoj, M. Menvielle, I. Michaelis, N. Olsen, J. Rauberg, M. Rother, T. J. Sabaka, A. Tangborn, L. Tøffner-Clausen, E. Thébault, A. W. P. Thomson, I. Wardinski, Z. Wei, and T. I. Zvereva, "International geomagnetic reference field: The eleventh generation," Geophys. J. Int., vol. 183, no. 3, pp. 1216-1230, 2010.

[28] C. L. Rino and E. J. Fremouw, "The angle dependence of singly scattered wavefields," J. Atmos. Terrestrial Phys., vol. 39, no. 8, pp. 859-868, 1977.

[29] R. R. Robins, J. A. Secan, and E. J. Fremouw, "A mid-latitude scintillation model," Tech. Rep. NWRA-86-R0004, Northwest Res. Assoc., Univ. Bellevue, WA, USA, 1986.

[30] D. L. Knepp, "Multiple phase-screen calculation of the temporal behavior of stochastic waves," Proc. IEEE, vol. 71, no. 6, pp. 722-737, Jun. 1983.

[31] G. Gustafsson, N. E. Papitashvili, and V. O. Papitashvili, "A revised corrected geomagnetic coordinate system for epochs 1985 and 1990," J. Atmos. Terrestrial Phys., vol. 54, nos. 11-12, pp. 1609-1631, 1992.

[32] M. Hansen, R. S. DeFries, J. R. G. Townshend, M. Carroll, C. Dimiceli, and R. A. Sohlberg, "Global percent tree cover at a spatial resolution of 500 meters: First results of the MODIS vegetation continuous fields algorithm," Earth Interact., vol. 7, no. 10, pp. 1-15, 2003.

[33] J. Chen, S. Quegan, and X. J. Yin, "Calibration of spaceborne linearly polarized low frequency SAR using polarimetric selective radar calibrators," Progr. Electromagn. Res., vol. 114, pp. 89-111, Feb. 2011.

[34] P. López-Dekker, J. A. Garcia, F. De Zan, T. Borner, M. Younis, K. Papathanassiou, T. Guardabrazo, V. Bourlon, S. Ramongassie, N. Taveneau, L. Ulander, D. Murdin, N. Rogers, S. Quegan, and R. Franco, "BIOMASS end-to-end mission performance assessment," in Proc. Int. Geosci. Remote Sens. Symp., Jul. 2012, pp. 1602-1605.

[35] R. Scheiber, S.-K. Lee, K. P. Papathanassiou, and N. Floury, "Extrapolation of airborne polarimetric and interferometric SAR data for validation of bio-geo-retrieval algorithms for future spaceborne SAR missions," in Proc. IEEE Int. Geosci. Remote Sens. Symp., vol. 2, Jul. 2009, pp. 941-944.

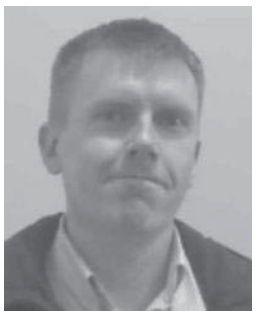

Neil C. Rogers received the B.Sc. degree in physics from the University of Durham, Durham, U.K., in 1992, the M.Sc. degree in astronautics and space engineering from the University of Cranfield, Cranfield, U.K., in 1994, and the Ph.D. degree from the University of Leicester, Leicester, U.K., in 2000, for research into the ionospheric impacts on HF direction finding systems.

He was a Senior Scientist with the Centre for RF Propagation and Atmospheric Research at QinetiQ (formerly the U.K. Defence Research Agency), in 2010. He researched ionospheric impacts on over-the-horizon radar, UHF satellite tracking radar, space-based radar, GPS and Galileo satellite navigation systems, UHF satellite communications, and HF/MF digital broadcasting. Since October 2010, he has been a Research Associate with the Centre for Terrestrial Carbon Dynamics, University of Sheffield, Sheffield, U.K., assessing the impacts of the ionosphere on spaceborne polarimetric interferometric SAR.

Dr. Rogers is a Chartered Physicist and member of the U.K. Institute of Physics.

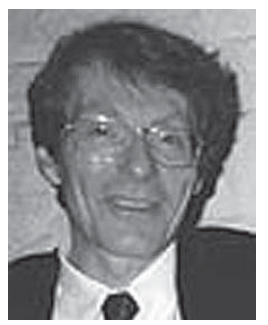

Shaun Quegan (M'90) received the B.A. and M.Sc. degrees in mathematics from the University of Warwick, Coventry, U.K., in 1970 and 1972, respectively, and the Ph.D. degree from the University of Sheffield, Sheffield, U.K., in 1982.

He was a Research Scientist with the Marconi Research Centre, Great Baddow, U.K., from 1982 to 1986, and led the Remote Sensing Applications Group from 1984 to 1986 . He established the SAR Research Group, University of Sheffield, in 1986, whose success led to his Professorship awarded in 1993. He helped to inaugurate the Sheffield Centre for Earth Observation Science, of which he remains the Director. In 2001, he became the Director of the U.K. National Environmental Research Council Centre for Terrestrial Carbon Dynamics. This multi-institutional centre is concerned with assimilating earth observation and other data into process models of the land component of the carbon cycle, and now forms part of the U.K. National Centre for Earth Observation. His current research interests include physics, systems and data analysis aspects of radar remote sensing are now subsumed in the more general aim of exploiting many sorts of EO technology to give greater quantitative understanding of the carbon cycle.

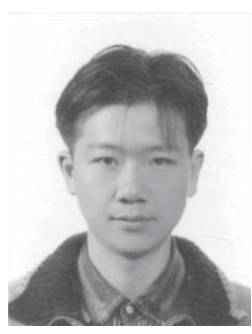

Jun Su Kim was born in Busan, Korea, in 1982. He received the Bachelor and Master's degrees in earth environmental sciences from Seoul National University, Seoul, Korea, in 2004 and 2007, respectively. $\mathrm{He}$ is continuing the Ph.D. studies on the development of mitigation schemes against ionospheric effects on SAR data with the German Aerospace Center, Oberpfaffenhofen, Germany since 2008.

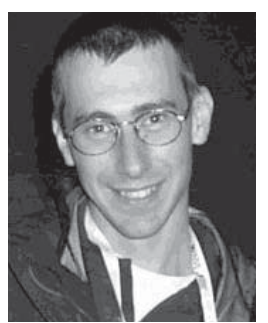

Konstantinos P. Papathanassiou received the Dipl. Ing (Hons.) and the Dr. degrees (Hons.) from the Technical University of Graz, Graz, Austria, in 1994 and 1999, respectively. 